\title{
Increase of the aerosol hygroscopicity by cloud processing in a mesoscale convective system: a case study from the AMMA campaign
}

\author{
S. Crumeyrolle ${ }^{1}$, L. Gomes ${ }^{1}$, P. Tulet ${ }^{1}$, A. Matsuki ${ }^{2}$, A. Schwarzenboeck ${ }^{2}$, and K. Crahan ${ }^{1}$ \\ ${ }^{1}$ GAME/CNRM, METEO-FRANCE - CNRS, Toulouse, France \\ ${ }^{2}$ Laboratoire de Meteorologie Physique, Clermont-Ferrand, France
}

Received: 6 March 2008 - Published in Atmos. Chem. Phys. Discuss.: 29 May 2008

Revised: 3 September 2008 - Accepted: 18 September 2008 - Published: 1 December 2008

\begin{abstract}
Aerosol properties were measured during an airborne campaign experiment that took place in July 2006 in West Africa within the framework of the African Monsoon Multidisciplinary Analyses (AMMA). The goal of the present study was to determine the main microphysical processes that affect the aerosols during the passage of a mesoscale convective system (MCS) over the region of Niamey in Niger. A significant change in the aerosol profiles measured before and after the passage of the MCS was found in a layer located between 1300 and $3000 \mathrm{~m}$, where the aerosol concentration drastically decreased after the passage of the MCS. Concurrently, a significant increase in the cloud condensation nuclei $(\mathrm{CCN})$ fraction was also observed during the post-MCS period in the same layer. Moreover, the results of the elemental composition analyses of individual particles collected in this layer after the MCS passage have shown higher contributions of sulfate, nitrate and chloride to the total aerosol mass. A mesoscale atmospheric model with on-line dust parameterization and Lagrangian backtrajectories was used to interpret the impact of the MCS on the aerosol properties. The results of the simulation show that the MCS 1) generates dust particles at the surface in the gust front of the system and washout of particles during the system precipitation, 2) modifies the aerosol mixing state (intensive aerosol property) through cloud processing, and 3) enhances CCN activity of particles through coating by soluble material.
\end{abstract}

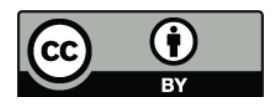

Correspondence to: S. Crumeyrolle (suzanne.crumeyrolle@cnrm.meteo.fr)

\section{Introduction}

The interactions between aerosols and clouds have a large influence on the role of aerosols in climate change. These interactions mainly depend on the particle characteristics (concentration, size, composition, hygroscopic properties, mixing state) and the type of clouds involved (continental or maritime, convective or stratiform, cold or warm). These interactions are complex because the aerosol characteristics can be modified by in-cloud processes. The atmospheric aerosols affect cloud formation through their role of cloud condensation nuclei $(\mathrm{CCN})$. In return, the clouds affect the aerosol particles through cloud processing by changing their concentration in the atmosphere through scavenging or by modifying their properties through chemical reactions that take place in the drops (or on ice crystals).

There have been few field observations and measurements related to the impact of cloud formation on the evolution of aerosol properties. Levin et al. (1996), looking at the effects of dust and sulfate on cloud formation, found that dust particles were coated with sulfate due to in-cloud processing. A few results obtained from modeling studies mention the role of clouds in modifying aerosols. For example, using a numerical model, Yin et al. (2002) showed that insoluble mineral dust can become effective $\mathrm{CCN}$ after passing through a convective cloud. Wurzler et al. (2000) shows that cloud processing of dust particles is a possible effective pathway to form soluble coatings on dust particles. Furthermore, this study shows that after one or two cycles of particles through convective clouds the contribution of gas uptake by drops and subsequent liquid phase oxidation add considerable soluble material to dust particles. 

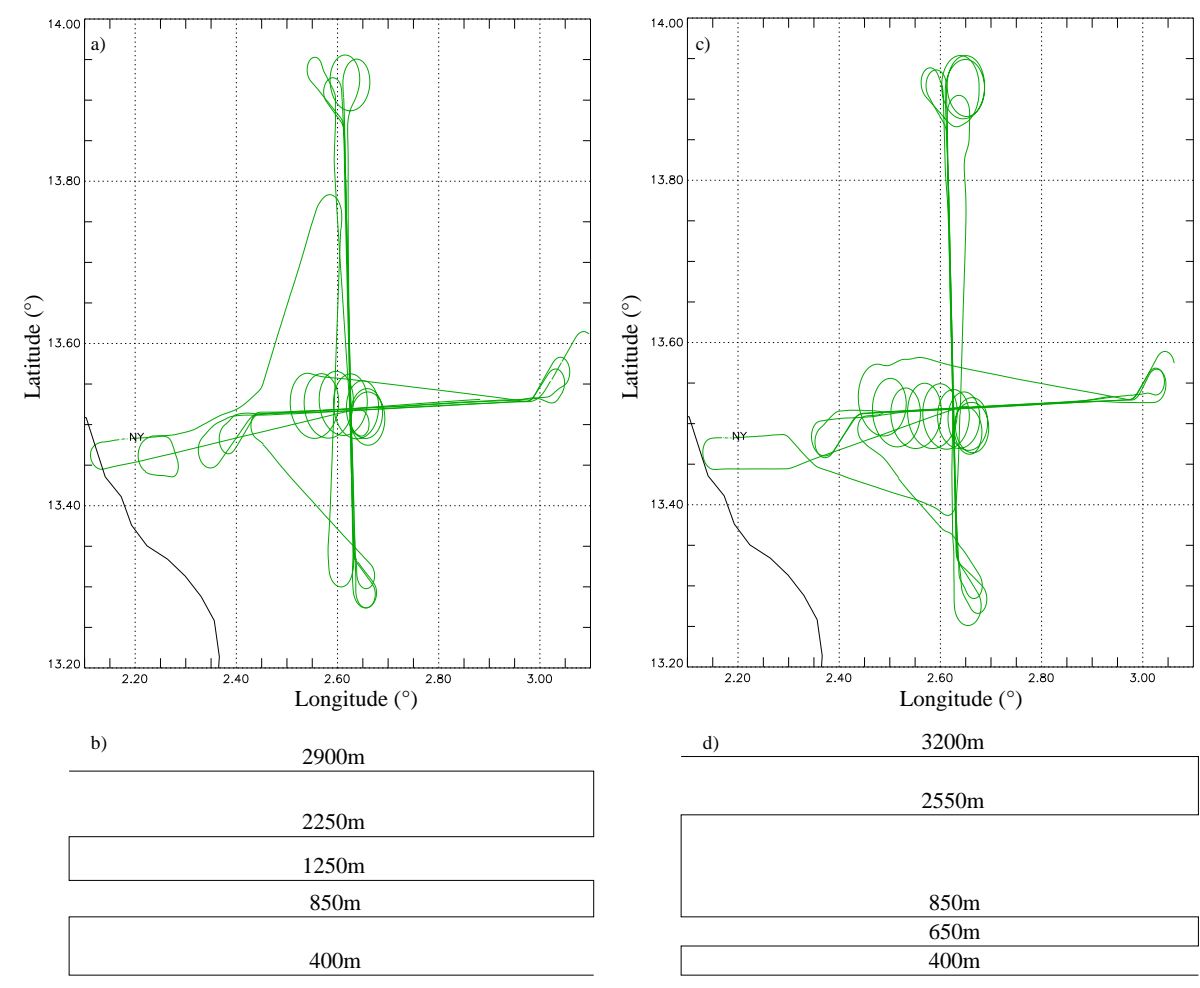

Fig. 1. Horizontal and vertical ATR-42 trajectories (a and b) on 1 July 2006, at 12:00 UTC and (c and d) on 2 July 2006, at 12:00 UTC.

Africa is a well designed region for obtaining field observations and measurements to study the processes involved in the interactions between convective clouds and mineral dust. In Africa, precipitation mostly occurs due to the formation of mesoscale convective systems (MCS) during the monsoon season when air masses containing a variety of aerosol types converge from different sources. The air mass circulation is formed by south and north trade winds converging toward the Inter Tropical Discontinuity (ITD). The continental north easterly trade is called Harmattan and the south westerly trade is called monsoon flux. These two major fluxes create two distinct layers characterized by different aerosol properties: the monsoon layer (ML) and the Saharan Air Layer (SAL) (Carlson and Prospero, 1972; Prospero and Carlson, 1972). In the ML, the monsoon flux transports marine air masses over the continent where they are mixed with anthropogenic, biogenic and other sources of aerosols. The monsoon layer is affected by the land surface on diurnal timescales, through convection and shallow cumulus clouds in the well mixed boundary layer. Aerosols are modified and their properties are highly dependent on the environmental conditions during the transport. North of the ITD and above the ML is the SAL, which can be characterized by high dust content, consistent with low visibility (Karyampudi et al., 1999). The SAL is decoupled from the surface below and is more closely linked to the desert regions (Parker et al., 2005). The presence of aerosol in the SAL is connected to long range transport from Sahelian and Saharan regions. However, the formation of convective systems can entrain humid ML air into the SAL and dry SAL air into the ML. This mesoscale process erodes the thickness of the SAL and dries the monsoon layer (Parker et al., 2005). This process can also modify dust particles and enhance their CCN activity when they reenter subsequent clouds.

The African Monsoon Multidisciplinary Analysis (AMMA) program was designed to improve our knowledge on the African monsoon and its variability. A detailed description on the project is available at www.amma-international.org/. One of the objectives of the project was to investigate the cloud-aerosol interactions and particularly the role of aerosols in the African monsoon system. Several intensive campaigns of aerosol and cloud measurements were carried out between 1 June and 25 August 2006 in the western African region including both airborne and ground measurements.

The goal of the present study is to determine the microphysical processes that affect the aerosols during the passage of a convective system by comparing the vertical distribution and the physical and chemical properties of the aerosols before and after the convective system. For this purpose, airborne measurements were conducted in July 2006 over Banizoumbou in Niger during a Mesoscale Convective System mission of the AMMA experiment. 


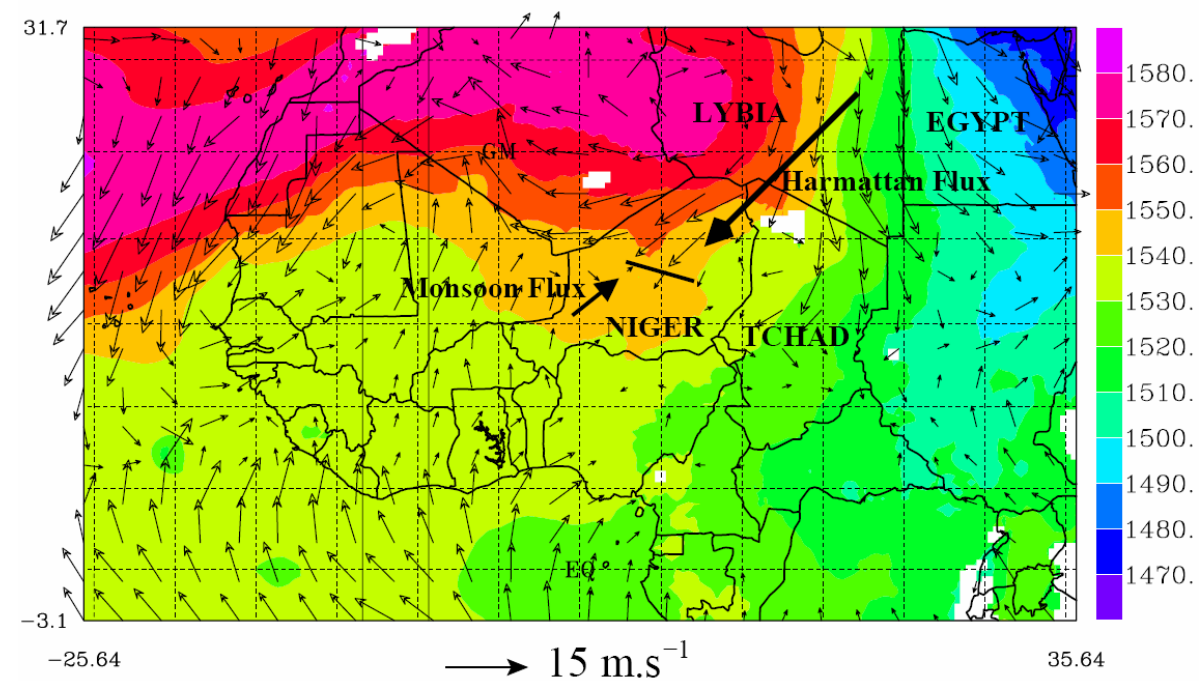

Fig. 2. ECMWF analysis of the height (m) of the geopotential at $850 \mathrm{hPa}$ and wind direction at $850 \mathrm{hPa}$ on $1 \mathrm{July} 2006$, at $12: 00 \mathrm{UTC}$. The maximum vector corresponds to horizontal wind speed of $12.6 \mathrm{~m} \mathrm{~s}^{-1}$.

This paper describes the results of profile measurements of aerosol and $\mathrm{CCN}$ concentration, aerosol size spectra and chemical composition during this period. Additionally, a mesoscale model with on-line dust parameterization and Lagrangian backtrajectories was used to interpret the impact of the MCS on the aerosol properties. The airborne sampling strategy is described in Sect. 2 as well as the data set of measured aerosol physical and chemical properties. The synoptic conditions and the MCS description are presented in Sect. 3. The observed results are presented in the Sect. 4, and a mesoscale simulation using an explicit representation of cloud and aerosol processes is then presented in Sect. 5 .

\section{Experimental strategy and instrumentation}

The measurements were performed during the Special Observation Period \#1a (SOP1a) of the AMMA experiment on the ATR-42 aircraft operated by the Service des Avions Français Instruments pour la Recherche en Environnement (SAFIRE). The aircraft was based at Niamey airport in Niger for the duration of the AMMA experiment and performed 11 research flights during this SOP of July 2006. Most of the flight patterns were centered on the surface measurement site of Banizoumbou, located $70 \mathrm{~km}$ east of Niamey. Sampling occurred on 1 and 2 July 2006, i.e. before and after the passage of a MCS over Niger. Generally both layers are present over Niger with weak exchanges occurring between them and are thus considered relatively homogeneous (because of long-range transport) in term of particle concentration and chemical composition. As explained above, the passage of mesoscale convective system allows the increasing of inter- actions between both layers (Boundary Layer and Saharan Air layer). As the environmental conditions were the same during both flights, thus any difference in the aerosol properties could be mainly attributed to the impact of the MCS.

\subsection{Experimental strategy}

Both flights occurred during the early afternoon when the convective mixed layer grew relatively slowly. The flight plans (Fig. 1) were similar, i.e. same geographic location and same period of the day (from 11:30 UTC to 15:30 UTC). During both flights, two vertical soundings were made at the beginning and at the end of the flight, providing a rapid characterization of the inversion level and of the vertical profile of the thermodynamical and microphysical parameters. On 1 and 2 July, the ATR-42 flew above Banizoumbou along a cross flight-track with horizontal dimension of about $60 \mathrm{~km}$ (Fig. 1). The two axes of the cross flight-track were oriented North-South and West-East. Along these axes the ATR-42 flew at different altitudes, in the Boundary Layer (BL) and in the Saharan Air Layer (SAL). During the first flight (1 July), the ATR-42 flew five legs on each axis, two of them in the BL $(400 \mathrm{~m}$ and $850 \mathrm{~m})$ and three in the SAL $(1250 \mathrm{~m}, 2250 \mathrm{~m}$, $2900 \mathrm{~m}$ ). During the second flight (2 July), the ATR-42 flew five legs on each axis, three of them in the BL $(400 \mathrm{~m}, 650 \mathrm{~m}$, $850 \mathrm{~m})$ and two in the SAL $(2550 \mathrm{~m}, 3200 \mathrm{~m})$.

\subsection{Instrumentation}

Aerosol instrumentation was connected to the French community aerosol inlet (CAI) installed on the ATR-42. This isokinetic and isoaxial inlet has a 50\% detection efficiency 


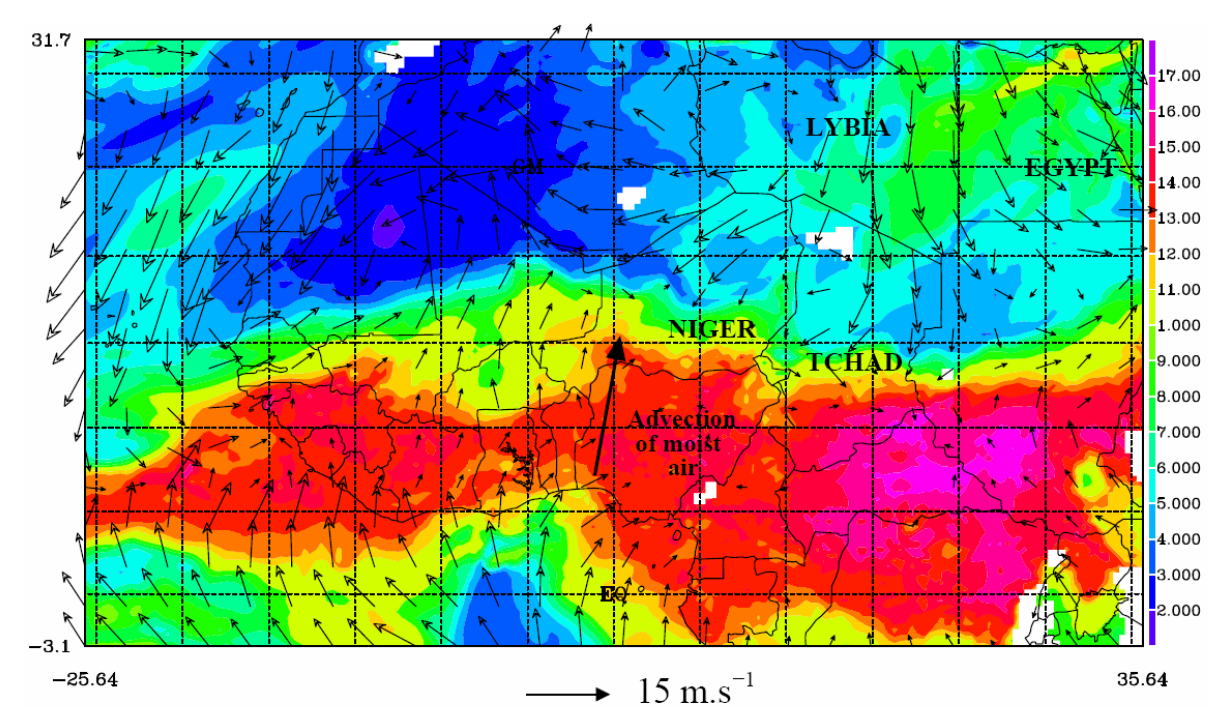

Fig. 3. ECMWF analysis of the water vapor mixing ratio $\left(\mathrm{g} \mathrm{kg}^{-1}\right)$ and wind direction at $850 \mathrm{hPa}$ on 1 July 2006 , at $12: 00 \mathrm{UTC}$. The maximum vector corresponds to horizontal wind speed of $12.6 \mathrm{~m} \mathrm{~s}^{-1}$.

estimated at $2.5 \mu \mathrm{m}$. Two condensation particle counters (CPC TSI model 3025 and 3010, respectively) were used to measure total ambient aerosol concentration $(\mathrm{CN})$ every $2 \mathrm{~s}$. Their efficiencies are of $100 \%$ for particle diameters ranging from 0.003 to $2.5 \mu \mathrm{m}$ and from 0.02 to $2.5 \mu \mathrm{m}$ respectively, and their relative uncertainties are about $5 \%$.

$\mathrm{CCN}$ measurements were made by using a static thermalgradient diffusion chamber (model 100-B, University of Wyoming) which operated similarly to the chamber described by Snider and Brenguier (2000). CCN number concentrations were determined every minute at supersaturations (SSs) ranging from 0.2 to $1 \%$ and $\mathrm{CCN}$ spectra were measured every five minutes. The instrument was calibrated just before the campaign. Its detection limit is approximately $50 \mathrm{~cm}^{-3}$ and the overall measurement uncertainty is about $\pm 15 \%$ at $1 \%$ SS and $\pm 30 \%$ at $0.2 \%$ SS.

Aerosol size distributions were measured using two instruments. A scanning mobility particle sizer (SMPS) was used to measure the number distribution of aerosol particles with diameters from 0.02 to $0.3 \mu \mathrm{m}$. This instrument consisted of a differential mobility analyzer (DMA) as described by Villani et al. (2007) and a CPC (TSI model 3010) for particle detection after the DMA. An optical particle sizer (OPS GRIMM model 1.108) provided particle size distributions ranging from 0.3 to $2 \mu \mathrm{m}$ equivalent optical diameter. Both instruments were calibrated before the campaign. Data collected were combined to provide a continuous size distribution between 0.02 and $2 \mu \mathrm{m}$ every $2 \mathrm{~min}$.

A two-stage low-volume impactor with $50 \%$ aerodynamic cutoff diameters of 0.2 and $1.6 \mu \mathrm{m}$ was used to collect particles on electron microscope grids (Matsuki et al., 2003).
Some grids were coated in advance with a thick layer of carbon in order to identify the particle shape and elemental composition (single particle analysis). In addition, some aerosol particle samples were collected on nitron-coated nitrocellulose films supported by Ni grids in order to identify nitrate as described by Mamane and Gottlieb (1992). Sampling duration was between 5 and 10 min depending on the atmospheric load. The morphology and chemical constituents of individual particles were analyzed using a Scanning Electron Microscopy (SEM) with an energy dispersive X-ray spectrometer (EDS). The criteria used for the particles identification are described by Matsuki et al. (2008): presence of a dust particle can be identified by the typical irregular shape and the dominant $\mathrm{X}$-ray peaks corresponding to $\mathrm{Al}$ and $\mathrm{Si}$; particles rich in $\mathrm{Cl}$ and $\mathrm{K}$ are linked to biomass burning; and particles found enriched by $\mathrm{P}$ and $\mathrm{K}$ may be attributed to biogenic origin. The ATR-42 was also equipped for the measurements of wind, turbulent fluxes, and atmospheric state parameters.

\section{Description of the situation on 1-2 July 2006}

\subsection{Synoptic conditions}

Figure 2 represents the height of the geopotential at $850 \mathrm{hPa}$ on 1 July 2006, 12:00 UTC, calculated from the ECMWF analysis. From this figure, two structures clearly appear: the north-west domain is dominated by high geopotential height $(1580 \mathrm{~m})$ while a low geopotential height $(1470 \mathrm{~m})$ is observed over Egypt and western Libya. The associated zonal pressure gradient is linked to strong northeasterly wind $\left(>8 \mathrm{~m} \mathrm{~s}^{-1}\right)$, as seen over Niger and Tchad. Over the center 


\section{a)}

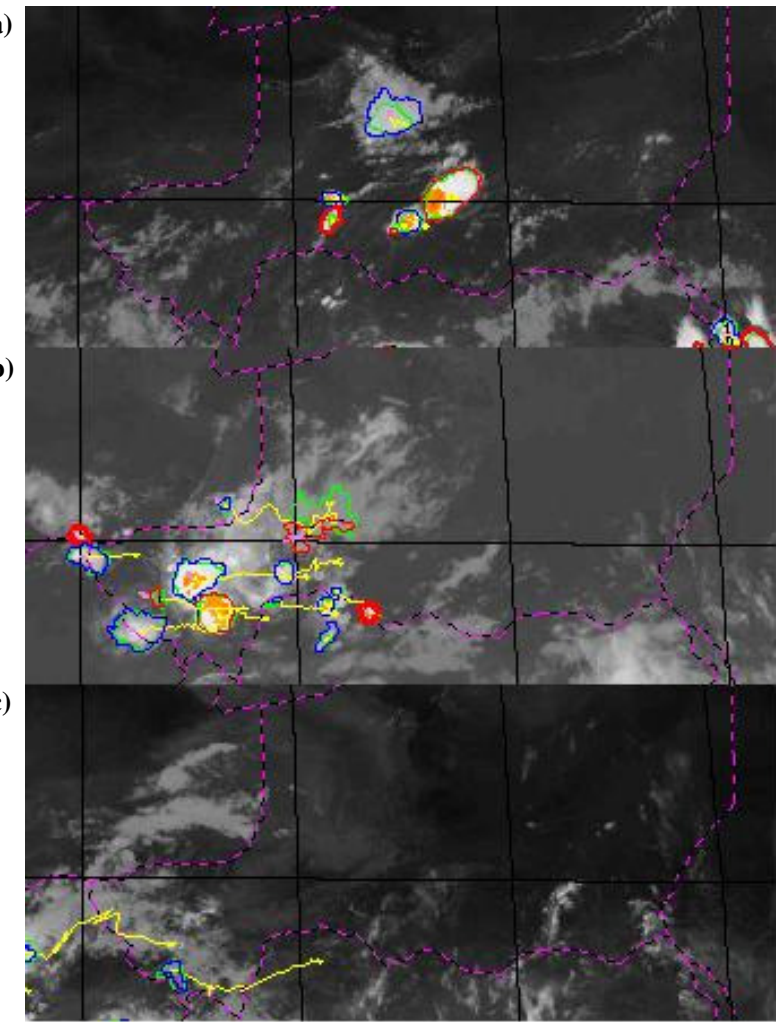

Fig. 4. MCS tracking images, (a) 1 July at 15:00 UTC, (b) 2 July at 00:00 UTC, (c) 2 July at 12:00 UTC. Source: aoc.amma-international. org/observation/mcstracking.

of Niger, the northeasterly air masses of the Harmattan (between 3 and $5 \mathrm{~m} \mathrm{~s}^{-1}$ ) and the southwesterly air masses of the monsoon flux (between 1 and $3 \mathrm{~m} \mathrm{~s}^{-1}$ ) converge and depict the Inter-Tropical Discontinuity (ITD).

Figure 3 is the ECMWF analysis on 1 July 2006, at 12:00 UTC, for the water vapor mixing ratio at $850 \mathrm{hPa}$. Larger values of the water mixing ratio $\left(>12 \mathrm{~g} \mathrm{~kg}^{-1}\right)$ are associated with the monsoon flux while smaller values $\left(<5 \mathrm{~g} \mathrm{~kg}^{-1}\right)$ characterize the Harmattan flux. This figure shows an intrusion of moist air corresponding to the advection by the monsoon flux around $14^{\circ} \mathrm{N} 5^{\circ} \mathrm{E}$. This intrusion brings humidity and heat near the ITD close to where a convective system occurs at 15:00 UTC. The presence of the wind convergence, humidity and heat at low levels allows the initiation and the propagation of a convective system.

\subsection{MCS description}

The initiation of the studied MCS occurs at the border between Niger and Nigeria $\left(15.04^{\circ} \mathrm{N}\right.$ and $\left.5.91^{\circ} \mathrm{E}\right)$ around 15:00 UTC on 1 July 2006. This zone was highlighted by the ECMWF analysis as favorable to convection. The MCS-tracking (Mathon et al., 2002) and Massachusetts Institute of technology (MIT) radar allowed us to watch the
MCS formation and to follow its trajectory along West Africa (data available at the AMMA Operational Center, aoc.amma-international.org/). Figure 4 is a representation of the MCS-tracking and shows the evolution of the MCS at the time of its formation (Fig. 4a), its maximum activity (Fig. 4b), and one day after its formation (Fig. 4c). The MCS was over Banizoumbou (Niger) at midnight (2 July 2006, 00:00 UTC), and vanished two days later over Guinea.

\subsection{Surface conditions}

For the AMMA special observation periods, late Juneearly July can be characterized as a dry period (Janicot et al., 2008). The precipitation record at Banizoumbou (http://aoc.amma-international.org/dir.php?current= 20060930\&dir=prod_NIAMEY/observation/) indicates that the MCS passage on 1 July corresponds to the first intense precipitation $(17 \mathrm{~mm})$. Dry conditions and low vegetation coverage make the Sahelian-Saharan region prone to dust events especially when surface wind speed exceeds a certain threshold. This threshold wind speed mainly depends on surface roughness elements, grain size and soil moisture (Marticorena and Bergametti, 1995). 


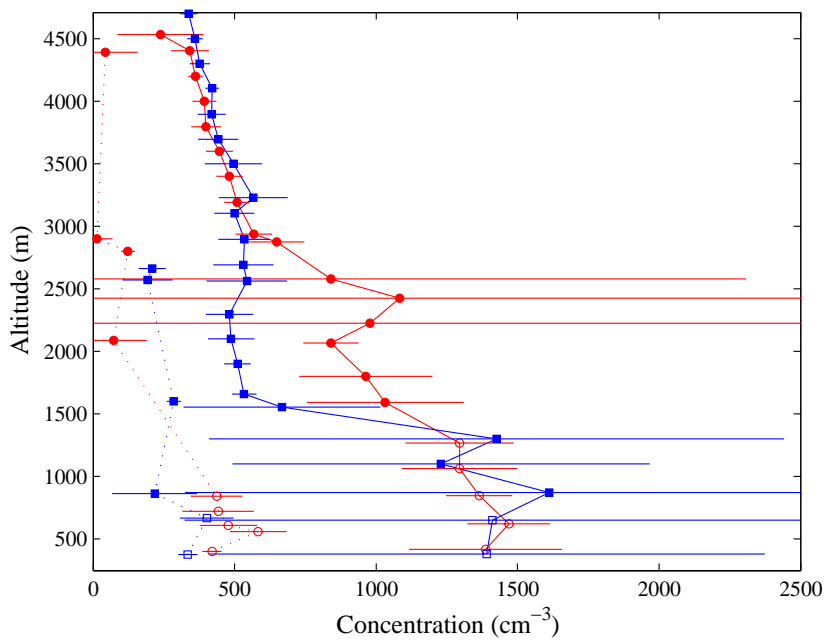

Fig. 5. $\mathrm{CN}$ total concentration (solid line) and $\mathrm{CCN}_{0.6}$ concentration (dotted line) as a function of altitude. Red dots are data collected on 1 July 2006, and blue squares are for those collected on 2 July 2006. The open symbols represent the data in the BL and solid symbols represent the data in the SAL. Horizontal bars correspond to the error bar of the average concentrations $( \pm 1 \sigma)$.

\section{Results}

The $\mathrm{CN}$ and $\mathrm{CCN}$ concentrations and the aerosol size distribution were first used to characterize the evolution of the hygroscopic properties of aerosols by comparing their microphysical properties (size, concentration) before and after the MCS passage. For both flights, except during the time of the vertical sounding, the CCN and aerosol spectra were compared to estimate the efficiency of the aerosols to serve as CCN. In Figs. 5, 6, and 7, the red (blue) color corresponds to data measured before (after) the MCS passage. It was observed that the MCS passage decreased the height of the BL as the inversion descended from $1500 \mathrm{~m}$ to $800 \mathrm{~m}$ after the passage of the MCS. Thus in Figs. 5, 6, and 7, open symbols indicate data measured within the BL while solid symbols correspond to data measured above the boundary layer.

\subsection{Aerosol concentration}

Figure 5 shows concentrations for the total aerosol $(\mathrm{CN})$ and the $\mathrm{CCN}$ (at a supersaturation of $0.6 \%, \mathrm{CCN}_{0.6}$ ) measured as a function of altitude during both flights. A strong vertical gradient of $\mathrm{CN}$ concentration is observed in the vertical profile. On 1 July, the total aerosol concentration was about $1350 \mathrm{~cm}^{-3}$ within the BL and varied between 1100 and $400 \mathrm{~cm}^{-3}$ within the SAL. On 2 July, the average concentration was about $1400 \mathrm{~cm}^{-3}$ in the BL. Above the BL, the aerosol concentration decreased more rapidly than the previous day to about $500 \mathrm{~cm}^{-3}$ at $3000 \mathrm{~m}$. The $\mathrm{CN}$ concentration drastically decreased after the passage of the MCS in an intermediate layer (a sub-layer of the SAL located between

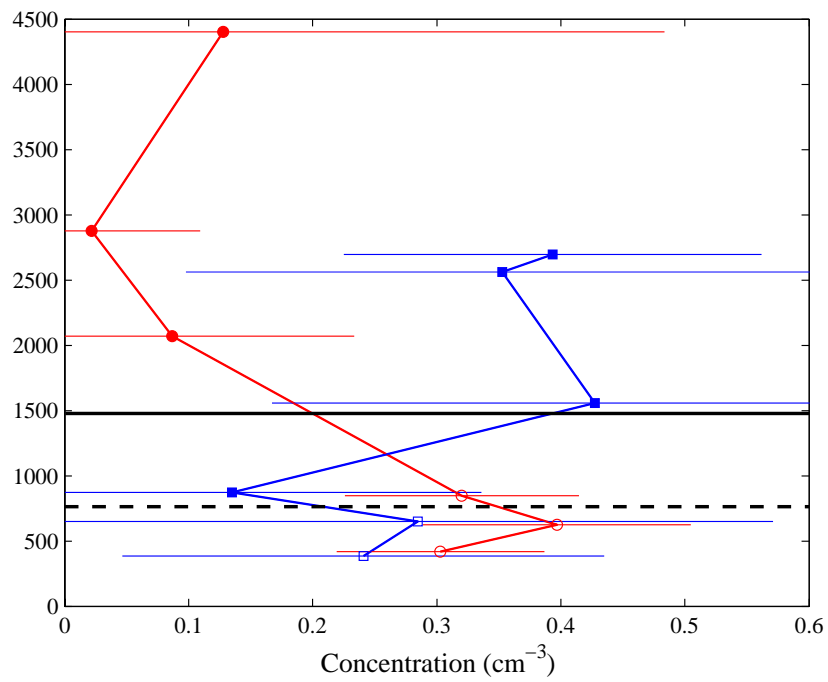

Fig. 6. $\mathrm{CCN}_{0.6} / \mathrm{CN}$ ratio as a function of altitude. Colors, symbols and horizontal bars are as in Fig. 5. The black horizontal solid (dotted) line correspond to the height of the BL before (after) the MCS passage.

1300 and $3000 \mathrm{~m}$ ), suggesting aerosol scavenging. In the BL, a large variability of the measurements is observed on both profiles, especially during the second flight, after the MCS passage.

Before the MCS passage, the $\mathrm{CCN}_{0.6}$ concentration shows a vertical gradient. The $\mathrm{CCN}_{0.6}$ number concentration is relatively high in the BL with a mean value of $450 \mathrm{~cm}^{-3}$, which is typical for continental environments. Above the $\mathrm{BL}$, the concentrations are close to free troposphere values $\left(50 \mathrm{~cm}^{-3}\right)$. After the MCS passage, the vertical gradient of the $\mathrm{CCN}_{0.6}$ concentration is no more visible. In the $\mathrm{BL}$, the $\mathrm{CCN}_{0.6}$ number concentration is similar to the one measured before the MCS passage. Above $1800 \mathrm{~m}$, the $\mathrm{CCN}_{0.6}$ concentration is higher $\left(>190 \mathrm{~cm}^{-3}\right)$ and at $2000 \mathrm{~m}$ the $\mathrm{CCN}_{0.6}$ concentration is 3 times larger than that measured before the MCS, suggesting cloud processing. Above $3000 \mathrm{~m}$, the $\mathrm{CCN}_{0.6}$ measurements were not available during the second flight because of a failure of the $\mathrm{CCN}$ chamber.

To quantify the changes of the $\mathrm{CN}$ and $\mathrm{CCN}_{0.6}$ concentrations and characterize the relationship between $\mathrm{CCN}_{0.6}$ and total aerosol population in the atmospheric column, the $\mathrm{CCN}_{0.6} / \mathrm{CN}$ ratio was introduced as a measure of hygroscopicity of the aerosol population. When this ratio is 0 , no activation of aerosols can occur to form cloud droplets while if this ratio is 1 , all aerosol particles can activate to become droplets. The measurements of the CPC 3010 were used to provide the $\mathrm{CN}$ concentration required to calculate the $\mathrm{CCN}_{0.6} / \mathrm{CN}$ ratio. Indeed, the measurements made with the CPC 3025 that include numerous particles of the nucleation mode cannot be used as reference for the $\mathrm{CN}$ concentration since these particles cannot act as CCN. 

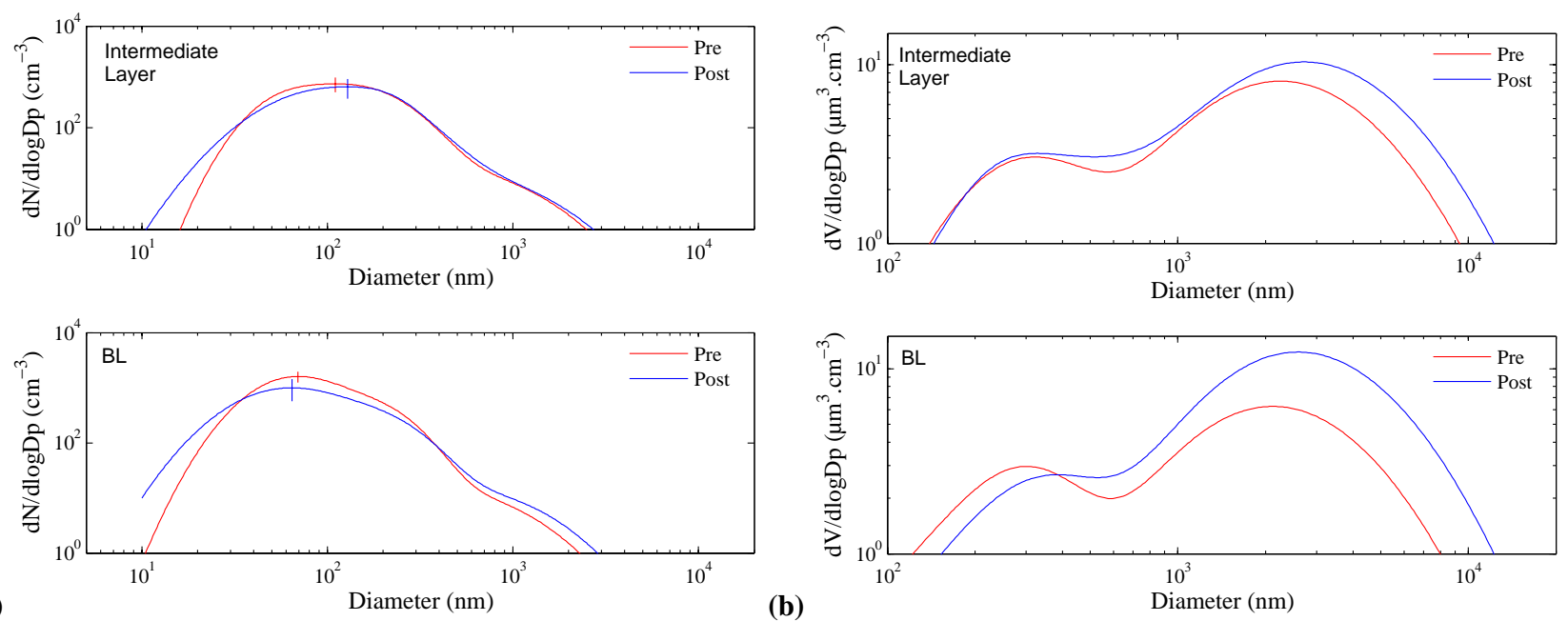

Fig. 7. (a) Average number-size distribution and (b) volume-size distribution observed by the SMPS and the OPS during 1 (red) and 2 (blue) July 2006, in the intermediate layer (top) and in the BL (bottom).

The variation with altitude of the $\mathrm{CCN}_{0.6} / \mathrm{CN}$ ratio is shown on Fig. 6. In the BL, before the MCS passage, the value of the $\mathrm{CCN}_{0.6} / \mathrm{CN}$ ratio ranged between 30 and $40 \%$. In the SAL during the same day, this ratio was less than $15 \%$. After the MCS passage, the $\mathrm{CCN}_{0.6} / \mathrm{CN}$ ratio was less than $30 \%$ in the BL, while in the SAL this ratio increased to $43 \%$. Figure 6 shows a significant increase of the $\mathrm{CCN}_{0.6}$ fraction within the SAL after the passage of the MCS, especially in the intermediate layer, while the ratio remained unchanged in the BL. Because the enhancement in $\mathrm{CCN}_{0.6}$ activity is mainly a function of particle size and chemical composition (Köhler, 1926), these properties are discussed in more detail below.

\subsection{Aerosol size distribution}

Submicron aerosol size distribution were inverted using software developed by the LaMP (Laboratoire de Météorologie Physique, University of Clermont-Ferrand, France), taking into account charging probabilities, counting efficiencies of the CPC and transfer functions of the DMA. The size distributions (in number) measured during each flight by combining the averaged output of the SMPS and the OPS were used to determine a mean distribution for each layer (BL and Intermediate layer). From these mean number distributions, a mean volume distribution was calculated for each layer as well. The mean distributions were fitted by using multi-modal lognormal distributions that best represent the measured distributions. A maximum of three modes were used to describe the number and volume distributions. The parameters of each mode of the lognormal fit (number or volume concentration, median diameter and geometric standard deviation) are shown in Tables 1 and 2, and the results are plotted on Fig. 7. Regarding total CN concentrations, a devi- ation is observed with the data given by the CPC 3010 which can be probably explained by a bad transfer function of the DMA used.

Aitken $\left(D_{p}<0.1 \mu \mathrm{m}\right)$, accumulation $\left(0.1<\mathrm{D}_{p}<0.5 \mu \mathrm{m}\right)$ and coarse $\left(\mathrm{D}_{p}>0.5 \mu \mathrm{m}\right)$ modes were present in both layers before and after the MCS passage. The presence of particles from a nucleation mode $\left(D_{p}<0.02 \mu \mathrm{m}\right)$ was also observed and can be shown (in Table 1) by comparing the measurements given by both CPCs (3010 and 3025). Airborne measurements already found evidence that new particle formation may occur near cloud boundaries (Roberts et al., 2001). Overall, the shape of the size distributions was almost the same and the contribution of each mode remained unchanged after the passage of the MCS. In particular, for particles with diameter larger than $30 \mathrm{~nm}$, no significant change of the aerosol size distribution appeared in the intermediate layer between both flights. This result suggests that the evolution observed in the intermediate layer regarding the $\mathrm{CCN}$ fraction cannot be attributed to a particle growth in this layer due to the passage of the convective system. Since the particle size cannot explain the enhancement of the $\mathrm{CCN}$ ratio observed in the intermediate layer, more information on the chemical composition of the particles is necessary.

As shown by Fig. 7, the volume distribution correlates well with the OPS measurement, as the concentration of particles with diameter larger than $0.5 \mu \mathrm{m}$ increases significantly in the BL after the MCS passage. This observation suggests an increased concentration of dust that can be verified by an analysis of particle composition.

\subsection{Single particle analysis}

Aerosol samples were collected periodically throughout the flights for analysis of their compositions using SEM-EDS. 
Table 1. Log-normal characteristics of the number spectra shown on Fig. 7a. C represents the concentration of the particle mode $\left(\mathrm{cm}^{-3}\right)$, $\sigma$ is the standard deviation and $D_{p}$ is the median diameter $(\mathrm{nm})$. The CN concentrations are given by the integration of the SMPS spectra (SMPS), and by observed measurements of the CPCs (CPC 3010 and CPC 3025).

\begin{tabular}{cccccccc}
\hline & \multicolumn{2}{c}{ Before the MCS passage } & \multicolumn{2}{c}{ After the MCS passage } \\
\hline \multirow{2}{*}{ Number distribution } & $\mathrm{C}\left(\mathrm{cm}^{-3}\right)$ & $\sigma$ & $D_{p}(\mathrm{~nm})$ & $\mathrm{C}\left(\mathrm{cm}^{-3}\right)$ & $\sigma$ & $D_{p}(\mathrm{~nm})$ \\
\hline & Mode1 & 822 & 1.6 & 70 & 641 & 1.8 & 60 \\
& Mode2 & 201 & 1.5 & 170 & 117 & 1.6 & 185 \\
Boundary layer & Mode3 & 8 & 2 & 500 & 9 & 2.0 & 615 \\
& SMPS & 1031 & & & 767 & & \\
& CPC 3010 & 1350 & & & 1400 & & \\
& CPC 3025 & 1900 & & & 2100 & & \\
& & & & & & & \\
Intermediate layer & Mode1 & 161 & 1.5 & 63 & 428 & 1.9 & 110 \\
& Mode2 & 360 & 1.6 & 140 & 42 & 1.3 & 190 \\
& Mode3 & 9 & 2 & 535 & 6 & 2.0 & 650 \\
& SMPS & 530 & & & 476 & & \\
& CPC 3010 & 850 & & & 550 & & \\
& CPC 3025 & 1050 & & & 600 & & \\
\hline
\end{tabular}

Table 2. Log-normal characteristics of the volume spectra shown on Fig. $7 \mathrm{~b} . \mathrm{C}$ represents the concentration of the particle mode $\left(\mu \mathrm{m}^{3} \mathrm{~cm}^{-3}\right)$, $\sigma$ is the standard deviation and $D_{p}$ is the median diameter $(\mathrm{nm})$.

\begin{tabular}{lcccccccc}
\hline & & \multicolumn{3}{c}{ Before the MCS passage } & \multicolumn{3}{c}{ After the MCS passage } \\
\multicolumn{2}{c}{ Volume distribution } & $\mathrm{C}\left(\mu \mathrm{m}^{3} \mathrm{~cm}^{-3}\right)$ & $\sigma$ & $D_{p}(\mathrm{~nm})$ & $\mathrm{C}\left(\mu \mathrm{m}^{3} \mathrm{~cm}^{-3}\right)$ & $\sigma$ & $D_{p}(\mathrm{~nm})$ \\
\hline \multirow{3}{*}{ Boundary layer } & Mode1 & 0.4 & 1.6 & 137 & 0.4 & 1.8 & 185 \\
& Mode2 & 1.3 & 1.5 & 305 & 1.1 & 1.6 & 365 \\
& Mode3 & 5 & 2 & 2120 & 9 & 2 & 2590 \\
\multirow{6}{*}{ Intermediate layer } & & & & & & & \\
& Mode1 & 0.05 & 1.5 & 102 & 0.2 & 1.3 & 250 \\
& Mode2 & 1.6 & 1.6 & 305 & 2 & 1.9 & 390 \\
& Mode3 & 6.1 & 2 & 2260 & 8 & 2 & 2730 \\
\hline
\end{tabular}

The distribution of the elemental composition of the particles as a function of size was determined by analyzing several tens of particles from four samples. One was taken before the MCS passage in the intermediate layer (at an altitude of $2790 \mathrm{~m}$ ) and the three others after the MCS passage (one in the BL at $394 \mathrm{~m}$ and two in the intermediate layer at 2493 and $3090 \mathrm{~m}$ ). The analysis distinguished between fine $\left(0.2 \mu \mathrm{m}_{i} D_{p}<1.6 \mu \mathrm{m}\right)$ and coarse fraction of particles $\left(D_{p}>1.6 \mu \mathrm{m}\right)$ and the frequency of occurrence of the main elements was determined. It should be noted that results presented here are in number fractions and that particles smaller than $0.2 \mu \mathrm{m}$ were not analyzed for their chemical composition by EDS due to the low signal-to-noise ratio when using a beam energy low enough to avoid evaporation of the particles.

As expected, the most abundant component found in the BL after the MCS passage was mineral dust (47\%, Table 3). Most of the X-ray spectra showed an abundance of $\mathrm{Al}, \mathrm{Si}$ and Fe characteristic of the presence of crustal components.
None of these dust particles contained soluble compounds (sulfate, nitrate etc.) suggesting that the BL was enriched with freshly emitted dust. This dust abundance in the BL correlates with the increase in concentration of coarse particles observed in the BL on Fig. 7b. This result indicates that dust particles of the coarse mode emitted during the passage of the MCS are sedimenting in the BL after the passage of the MCS. However, dust is generally thought of as water insoluble. Therefore, its efficiency to serve as $\mathrm{CCN}$ is rather low. The processing cannot be fully described from the available observations but the presence of non hygroscopic particles (like mineral dust) in the $\mathrm{BL}$ can explain that the $\mathrm{CCN}_{0.6}$ fraction remains the same in both flights. The other principal particle types found on this sample were sulfate particles (26\%), biomass burning particles (13\%) and carbon particles $(4 \%)$. The sea-salt particles were present in very low concentrations and the undetermined fraction of particles represented about $10 \%$. 

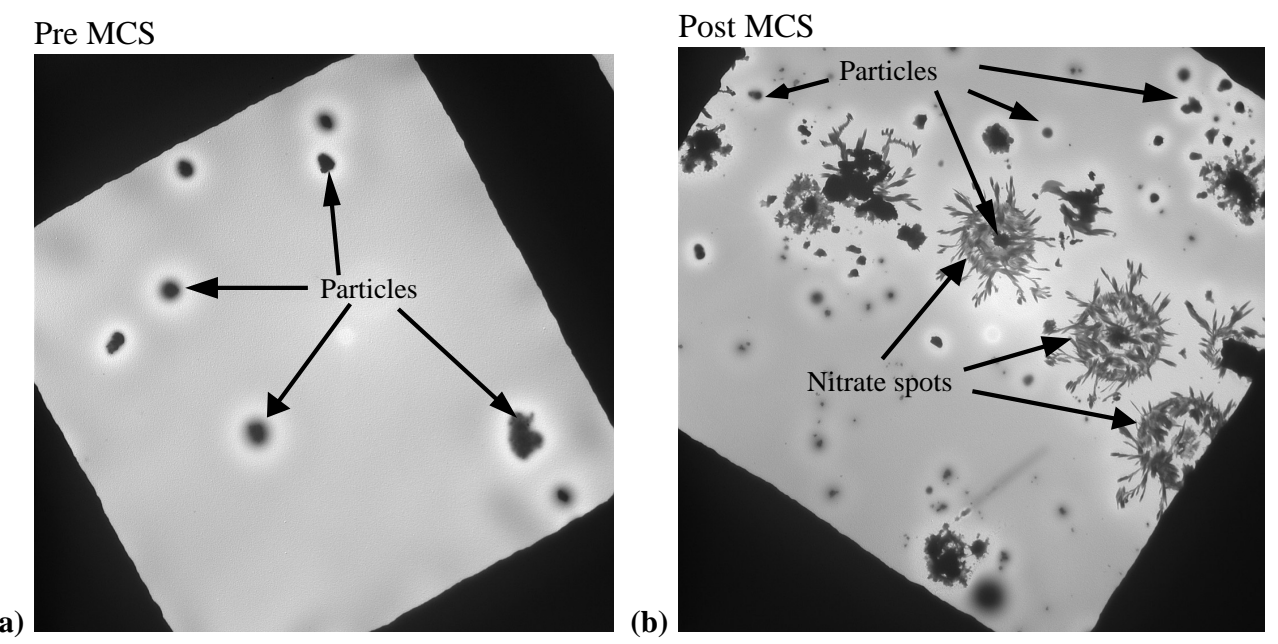

Fig. 8. SEM photographs showing particles collected on the first impactor stage $\left(D_{p}>1.6 \mu \mathrm{m}\right)$ on a nitron filter (a) sampling at $2790 \mathrm{~m}$ during 1 July 2006 flight and (b) sampling at 3090 m during 2 July 2006 flight.

Table 3. Various types of sub-micron particles $\left(\mathrm{D}_{p}<1 \mu \mathrm{m}\right)$ and their relative abundance found before and after the MCS passage. These results come from the single particle analysis on substrate sampled in the boundary layer and in the intermediate layer

\begin{tabular}{ccccccc}
\hline & \multicolumn{2}{c}{ Before the MCS passage } & \multicolumn{2}{c}{ After the MCS passage } \\
& Dust & Sulfate & Biomass burning & Dust & Sulfate & Biomass burning \\
\hline Boundary layer & & & & $47 \%$ & $26 \%$ & $13 \%$ \\
Intermediate layer & $48 \%$ & $12 \%$ & $32 \%$ & $18 \%$ & $43 \%$ & $33 \%$ \\
\hline
\end{tabular}

According to the single particle analysis of the fine fraction, a large difference of composition is observed between the samples that were taken on carbon-coated grids in the intermediate layer during both flights. Before the MCS passage, most particles $(48 \%)$ contain $\mathrm{Al}$ and $\mathrm{Si}$ with a high percentage occurrence of iron, suggesting a mineral composition. Among the other particles, the sulfate-containing particles represent only $12 \%$ of the total number of particles observed. The samples taken after the MCS passage reveal a large change in the occurrence of components. Elements such as $\mathrm{Al}$ and $\mathrm{Si}$ were found with lower frequencies in the accumulation mode of particles. Mineral dust particles represented only $18 \%$ of the particles while the frequency of occurrence of sulfate particles increased markedly up to $43 \%$. In addition, a significant number of dust particles contained sulfate $(33 \%)$ or chloride $(11 \%)$, suggesting that, contrary to what was observed in the BL, the surface properties of the mineral dust particles may have been altered by a coating of soluble elements.

Large differences were also observed between the samples that were taken on nitron-coated grids in the intermediate layer, before and after the passage of the MCS. The particles of the coarse fraction collected on nitron-coated grids were analyzed to identify those containing nitrate (Mamane and Pueschel, 1980). Indeed, the nitron-coated substrate captures and, after octanol vapor exposition, crystallizes nitrate on the substrate surface. Nitrate, like sulfate or ammonium, is water soluble and can increase the efficiency of a particle to serve as CCN. However, several previous experimental analyses have indicated that sulfates are primarily found in the fine mode while nitrates are predominantly found in the coarse mode $(>1 \mu \mathrm{m}$ ) (Dentener et al., 1996; Murphy and Thompson, 1997; Gard et al., 1998; Zhuang et al., 1998). Figure 8a and $\mathrm{b}$ show photomicrographs of the nitron-coated substrates used to collect coarse particles on 1 July (at $2790 \mathrm{~m}$ ) and on 2 July (at $3090 \mathrm{~m}$ ), respectively. Figure 8 b clearly shows the reactivity spot around large particles (visible at the center of the spot) surrounded by elongated fibers that are characteristic of the chemical reaction of nitrate with the nitron film. Figure 8a shows no such reaction of nitron substrate with the particles (Isawa and Ono, 1979; Mamane and Pueschel, 1980; Mamane and Gottlieb, 1992). Therefore, the singleparticle analysis indicates the presence of nitrate on coarse particles (mainly mineral dust) collected during the postMCS period, suggesting a coating of this ionic component. A modification of the surface properties of dust particles by 
coating of a highly water soluble component such as nitrate (Seinfeld and Pandis, 1998) can enhance their hygroscopic properties (Levin et al., 1996). In addition, the high frequency of occurrence of nitrate in the aerosols of the intermediate layer suggests that most of the coarse particles are probably efficient CCN.

Levin et al. (1996) suggested different processes to explain the coating of soluble materials on core particles: coagulation of particles, gas to particles conversion, and cloud processing. In Niger, the major source of sulfate, chloride and nitrate is the marine air masses transported in the BL, from the southwest, by the monsoon flux. However, in this study, the particle coated with sulfate, chloride or nitrate were collected at about $1500 \mathrm{~m}$ above the top of the BL. Thus, we believe that a physical-chemical mechanism was able to lift up sulfate, chloride and nitrate particles from the BL to higher layer and then condensate sulfate, chloride or nitrate vapour on dust particles.

Finally, all the observations described above suggest that strong aerosol modifications (concentration profile, $\mathrm{CCN}_{0.6} / \mathrm{CN}$, mixing state) have been caused by the MCS passage. From the aerosol profiles, it appears that the $\mathrm{CN}$ concentration drastically decreased after the passage of the MCS in the intermediate layer located between 1300 and $3000 \mathrm{~m}$. In this same layer, a significant increase of the $\mathrm{CCN}_{0.6}$ concentration was observed during the post-MCS period. Moreover, the results of the elemental composition analyses of individual particles collected in this layer after the MCS passage demonstrate a higher contribution of sulfate, nitrate and chloride to the total aerosol (in internal and external mixing with mineral dust), all of which serving as soluble and efficient $\mathrm{CCN}$. We thus expect that MCS processing acted as a physical-chemical mechanism that is responsible for the enhancement of the $\mathrm{CCN}_{0.6} / \mathrm{CN}$ ratio observed in the intermediate layer during the post-MCS period. To complement the observations and interpret the results, a simulation exercise was carried out.

\section{Numerical modeling}

\subsection{Model description}

To interpret these results, the mesoscale, non hydrostatic atmospheric model MesoNH was used in this study. This model has been jointly developed by CNRM (Meteo France) and Laboratoire d'Aérologie (CNRS) (Lafore et al., 1998). MesoNH simulates atmospheric conditions in the small scale (LES type, horizontal resolution of a few meters) and synoptic scale (horizontal resolution of several tens of kilometers) and can be run in a two-way nested mode involving up to 8 nesting stages. Different sets of parameterization have been introduced for convection (Bechtold et al., 2001), cloud microphysics (Pinty and Jabouille, 1998; Cohard and Pinty, 2000), turbulence (Bougeault and Lacarrére, 1989), biosphere-atmosphere thermodynamic exchanges (ISBA) (Noilhan and Mahouf, 1996), urban-atmosphere interactions (Masson, 2000), lightning processes (Barthe et al., 2005), gaseous chemistry (Suhre et al., 1998; Tulet et al., 2003) and aerosol chemistry (Tulet et al., 2005).

Mineral dust emissions are parameterized by Grini et al. (2006). In this parameterization, the three dust aerosol populations proposed by Alfaro and Gomes (2001) are generated and transported by the ORILAM lognormal aerosol scheme (Tulet et al., 2005). Regarding emission processes, dust aerosols are mobilized using the Dust Entrainment and Deposition model (DEAD) (Zender et al., 2003) which calculates dust fluxes from wind friction speeds. The physical basis of the model is taken from Marticorena and Bergametti (1995) where dust fluxes are calculated as a function of saltation and sandblasting processes. Here, the emission of dust aerosols are calculated directly from ISBA surface parameters, and then sent to the atmosphere consistent with the fluxes of momentum, energy and humidity. Aerosol scavenging is explicitly determined according to a kinetic approach to calculate the aerosol mass transfer in cloud and rain droplets as defined by Seinfeld and Pandis (1998), Pruppacher and Klett (1997), and Tost et al. (2006). The in-cloud mass aerosol transfer into rain droplets by autoconversion and accretion processes have been introduced as described by Pinty and Jabouille (1998). The sedimentation of aerosol mass included in raindrops has been solved using a time splitting technique with an upstream differencing scheme of the vertical sedimentation raindrops flux. The release of aerosols into the air due to rain evaporation is assumed to be proportional to the water evaporated (Chin et al., 2000).

MesoNH uses the radiation code of the ECMWF (Fouquart and Bonnel, 1980; Morcrette and Fouquart, 1986; ECMWF, 2004) which computes the radiative fluxes of shortwave and longwave radiation. Clouds and aerosols in the shortwave are taken into account using the Delta Eddington transformation (Joseph et al., 1976). Regarding the shortwave effect, a refractive index of the dust aerosols was assigned according to that measured over the ground site of Djougou (Benin) during the AMMA campaign (Mallet et al., 2008). To determine the origin of the simulated air masses, the model uses Lagrangian backtrajectories as detailed by Gheusi and Stein (2002).

\subsection{Simulation configuration}

The simulation begins at 00:00 UTC on 29 June 2006, and ends at 00:00 UTC on 3 July 2006. Three two-way nested grid domains were used. The large domain $(36 \mathrm{~km}$ resolution) between $3.1^{\circ} \mathrm{S}$ and $31.7^{\circ} \mathrm{N}$ in latitude and $25.64^{\circ} \mathrm{W}$ and $35.64^{\circ} \mathrm{E}$ in longitude, gives a large scale synoptic view of west Africa. The first embedded domain $(12 \mathrm{~km}$ resolution) is centered over Northwest Nigeria and covers a large part of the AMMA campaign area (latitudes $4.3^{\circ} \mathrm{N}$ and $17.6^{\circ} \mathrm{N}$ and longitudes $4.19^{\circ} \mathrm{W}$ and $16.24^{\circ} \mathrm{E}$ ). The smallest 

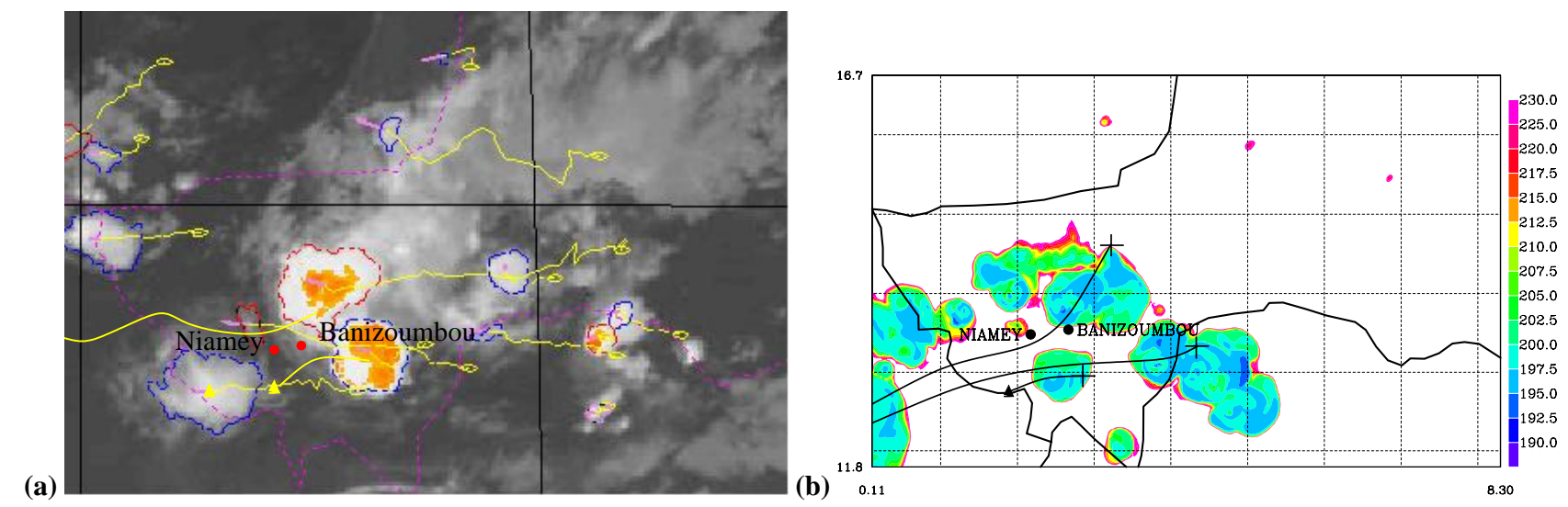

Fig. 9. Comparison between (a) observed satellite image on 2 July 2006, at 00:00 UTC (source: aoc.amma-international.org/observation/ mcstracking) and (b) modeled brightness temperature on 1 July 2006 at 19:00 UTC. On (a) (resp. b), the crosses correspond to the MCS initialisation, the yellow (black) lines correspond to the MCS trajectories and the yellow (black) triangles correspond to the MCS disappearance.

embedded domain ( $3 \mathrm{~km}$ resolution) gives a fine scale view of the Niger between $11.80^{\circ} \mathrm{N}$ and $16.82^{\circ} \mathrm{N}$ in latitude and $0.10^{\circ} \mathrm{E}$ and $8.31^{\circ} \mathrm{E}$ in longitude. The vertical resolution is composed of 60 stretched vertical levels reaching the altitude of $34000 \mathrm{~m}$; 30 levels are located in the boundary layer between the surface and $2000 \mathrm{~m}$.

Initialization and lateral boundary conditions of the large domain were taken from the ECMWF analysis. Vegetation types came from the ECOCLIMAP data base (Masson et al., 2003). The soil wetness index (SWI) was computed in offline mode using low level atmospheric data from the ECMWF forecast model merged with satellite precipitation data from the EPSAT-SG product (REF) and downwelling shortwave and longwave atmospheric radiative fluxes from the LANDSAF product (Trigo et al., 2008). This forcing data was then used as an upper boundary condition to drive the ISBA land surface model (Noilhan and Mahouf, 1996) from 2002-2006 in order to obtain a soil moisture state which is more realistic than that obtained from the operational NWP model. Boone and de Rosnay (2007) describe the forcing data and the methodology in more detail.

\subsection{Comparison between simulation and observations}

Figure 9a gives the Meteosat infrared picture on 2 July 2006 at 00:00 UTC and Fig. 9b shows the brightness temperature (Chaboureau and Pinty, 2006) simulated by MesoNH on 1 July 2006 at 19:00 UTC. Both simulations and MSG images show the development of a multiple convective system over the Niamey region. The two more intense systems are observed north and east of Banizoumbou. To follow their movement, the trajectory analysis was superimposed to the satellite image. The northern MCS was triggered east of the domain of Fig. $9 \mathrm{~b}$ and propagated from north of Niamey to Burkina Faso (west of the domain). The second system ob- served east of Banizoumbou moved slowly and disappeared south of Niamey. In our simulation, the two modeled systems appear in the Niamey region $5 \mathrm{~h}$ sooner than those observed on the brightness temperature map. The northern MCS evolves similarly to the observed one, but moves a bit more south, passing over Banizoumbou and Niamey whereas the observed trajectory of this system remains north of these locations. The MCS located east of Banizoumbou is simulated $0.5^{\circ}$ too far east and its propagation is quite different to the observed one. Instead of disappearing, the system merges with the northern one when passing south of Niamey. It is reasonable to estimate that the evolution of these two main systems is close enough to reality to use the simulation as a realistic tool to interpret the data. Nevertheless, the time delay of $5 \mathrm{~h}$ between simulation and observation will be taken into account in the following comparison.

The Atmospheric Radiation Measurement (ARM) ground site at Niamey airport (www.archive.arm.gov/) was an observation site to analyze the MCS passage and validate the simulation results. Figure 10 shows the evolution of temperature (a), pressure (b), wind speed (c) and accumulated rain water (d) observed and simulated by MesoNH. The $5 \mathrm{~h}$ of delay between the real and the simulated MCS's passage are retrieved on the surface field over Niamey by a decrease of the surface pressure and temperature, and an increase of surface wind and accumulated rainfall. From 20:00 UTC to 00:00 UTC on 1 July, the modeled and observed temperatures decrease $(-14 \mathrm{~K}$ and $-9 \mathrm{~K}$, respectively) as the result of a MCS downdraft that generates a gust front over $\mathrm{Ni}$ amey (respectively $15.3 \mathrm{~m} \mathrm{~s}^{-1}$ and $14.8 \mathrm{~m} \mathrm{~s}^{-1}$, Fig. 10c). On Fig. 10c, the passage of both MCSs is clear, at 19:00 UTC and 23:00 UTC, when the averaged wind speed is about $15.3 \mathrm{~m} \mathrm{~s}^{-1}$ and $14.2 \mathrm{~m} \mathrm{~s}^{-1}$, respectively. The ARM data, in accordance with the MCS trajectories seen on Fig. 9, 

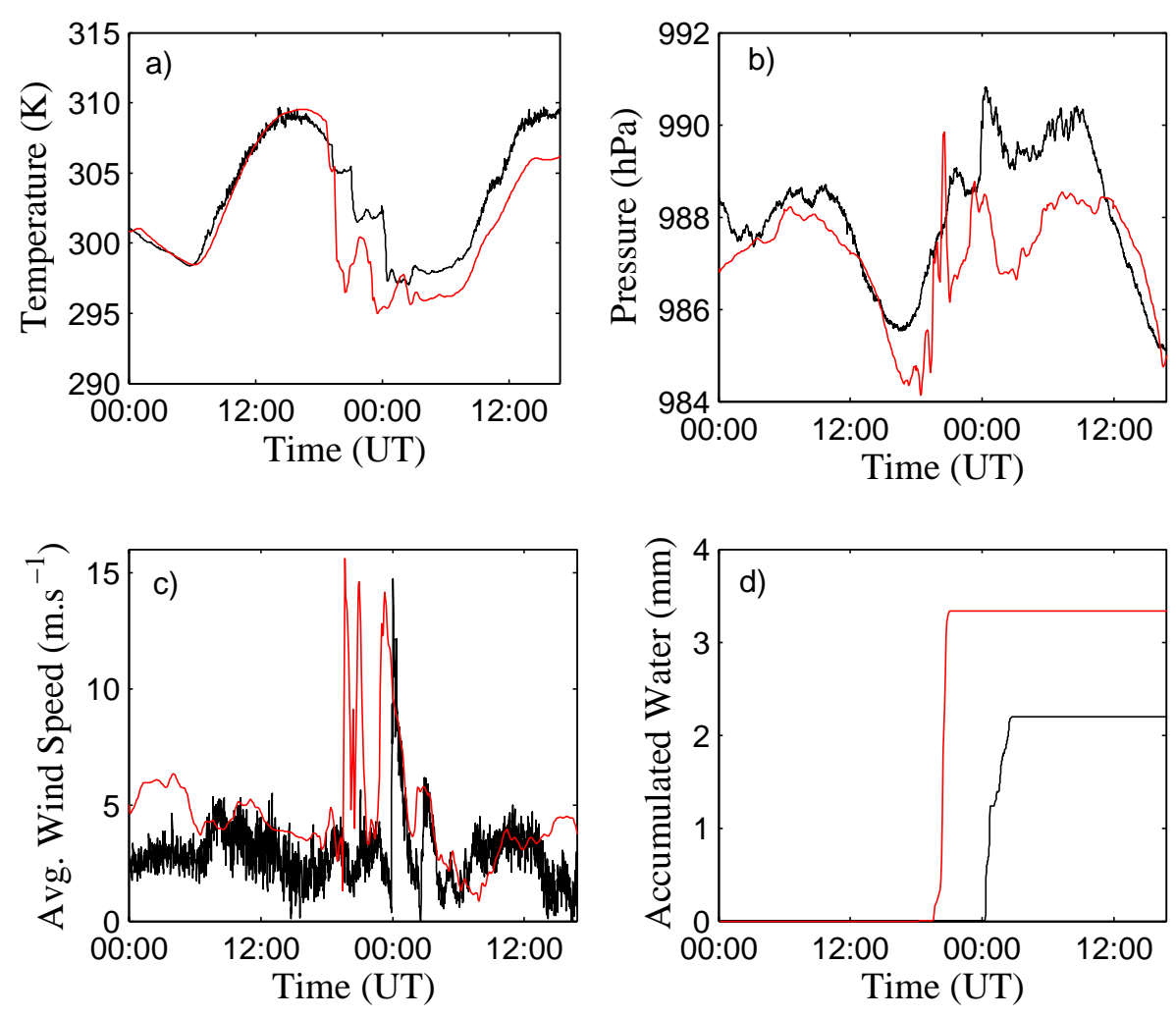

Fig. 10. Modeled (red line) and observed (black line) parameters (a) Temperature $\left({ }^{\circ} \mathrm{K}\right)(\mathbf{b})$ Pressure (hPa) (c) Averaged wind speed (m s $\left.{ }^{-1}\right)$ (d) Accumulated water (mm), from 1 July, 00:00 UTC to 2 July 18:00 UTC.

indicates only one MCS passage at 00:00 UTC over Niamey. Before and after the MCS passage, the observed and modeled wind speed are between 1 and $6 \mathrm{~m} \mathrm{~s}^{-1}$. It is important to note that the temperature decrease and the surface wind speed generated by the gust front are similar in the observation and in the model. The modeled precipitation rate (3.4 mm) (Fig. 10d) confirms only one MCS passage over Niamey. The delay observed between measured and simulated precipitation rates indicates that only the northern MCS precipitated. The simulated precipitation rate is higher than the observed precipitation rate $(2.2 \mathrm{~mm})$ suggesting that Niamey is directly affected by the convective core of the system in the simulation and mostly by the stratiform part of the system in reality.

The modeled and the observed atmospheric pressures (Fig. 10) are consistent during the 15 first hours of the 1 July 2006. Just before the MCS passage, the pressure value decreases to $984.3 \mathrm{hPa}$. From 1 July 18:00 UTC to 2 July 12:00 UTC, the modeled pressure is systematically underestimated. We can note that the MCS passage perturbs the atmospheric pressure. $17 \mathrm{~h}$ after the MCS passage, the modeled pressure compares well again with the observed pressure.
The aerosol number concentration measured as a function of altitude with the SMPS and the OPS during the ATR flight on 2 July between 12:00 UTC and 16:00 UTC (i.e. 12 to $16 \mathrm{~h}$ after the MCS passage) were averaged and converted to mass concentration in order to give the mean profile of aerosol mass concentration for the zone considered (i.e. $0.5^{\circ}$ around Banizoumbou; see Fig. 4). These data are compared to the vertical profile of dust mass concentration simulated over Banizoumbou on 2 July at 07:00, 08:00, 09:00 and 10:00 UTC, i.e. 12 to $16 \mathrm{~h}$ after the passage of the simulated MCS (Fig. 11a). A size cutoff of $2.5 \mu \mathrm{m}$ similar to the $50 \%$ detection efficiency of the aerosol inlet was applied to the calculation in order to compare simulated aerosol profiles to airborne observations for particles $<2.5 \mu \mathrm{m}$. In the boundary layer, between the surface and $900 \mathrm{~m}$ of height, the observations highlight a well-mixed layer with a steady concentration value of $60 \mu \mathrm{g} \mathrm{m}^{-3}$. On the other hand, simulated dust mass concentrations range from $200 \mu \mathrm{g} \mathrm{m}^{-3}$ at 07:00 UTC (not shown) to $50 \mu \mathrm{g} \mathrm{m}^{-3}$ at 10:00 UTC within a boundary layer of $450 \mathrm{~m}$ in thickness. This corresponds to a mean temporal value of $100 \mu \mathrm{g} \mathrm{m}^{-3}$. This overestimation can be interpreted as the consequence of the difference between the BL height observed between 12:00 and 16:00 UTC and that simulated between 07:00 and 10:00 UTC. In our simulation 
(a)

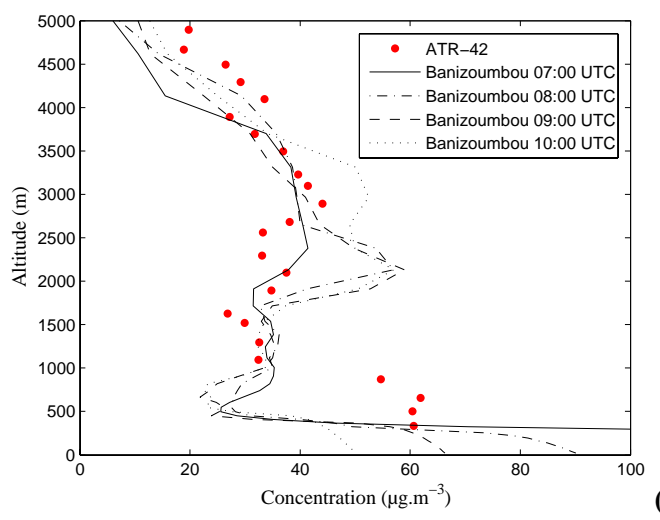

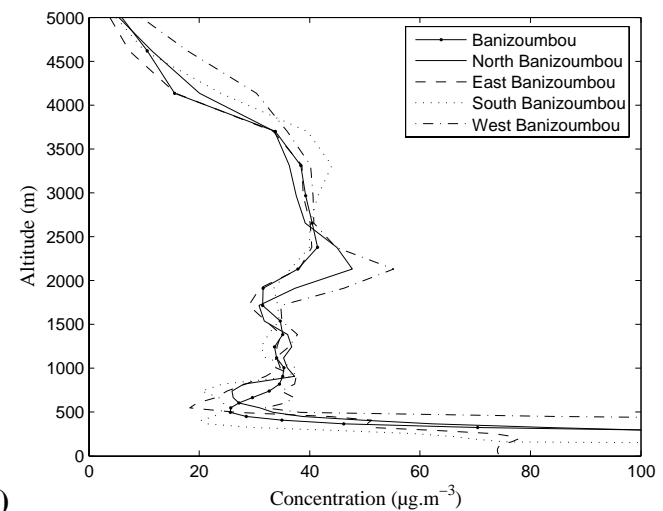

Fig. 11. (a) Comparison of modeled (lines) and observed (dots) vertical profiles of aerosol ( $\left.D_{p}<2.5 \mu \mathrm{m}\right)$ mass concentration over Banizoumbou. The measurements were made during the ATR-42 flight on 2 July 2006, between 11:00 UTC and 14:00 UTC. (b) Comparison of modeled vertical profile of the aerosol mass concentration over Banizoumbou, $0.5^{\circ}$ north of Banizoumbou, $0.5^{\circ}$ south of Banizoumbou, $0.5^{\circ}$ east of Banizoumbou and $0.5^{\circ}$ west of Banizoumbou on 2 July 2006, at 08:00 UTC (12 h after the MCS passage).

the aerosols present in the boundary layer are confined in the 450 first meters above the surface instead of being more diluted in a $900 \mathrm{~m}$ thick layer. Applying a dilution factor of 2 corresponding to the difference between both boundary layer thickness, the mean computed aerosol concentration $\left(50 \mu \mathrm{g} \mathrm{m}^{-3}\right)$ becomes comparable to the observation.

Above the boundary layer, two distinctive layers are observed. The first one, between 900 and $2800 \mathrm{~m}$, corresponds to a well-mixed layer with an aerosol mass concentration ranging between 27 and $35 \mu \mathrm{g} \mathrm{m}^{-3}$. The upper layer, separated from the intermediate layer by a maximum of $42 \mu \mathrm{g} \mathrm{m}^{-3}$ at $2800 \mathrm{~m}$, is characterized by a linear decrease of the dust concentration with altitude. The simulation results provide a similar vertical structure with the presence of three layers (Fig. 11a). An intermediate layer is also reproduced above the boundary layer with a quite constant concentration of aerosol of $25 \mu \mathrm{g} \mathrm{m}^{-3}$ at $700 \mathrm{~m}$ and $35 \mu \mathrm{g} \mathrm{m}^{-3}$ at $2000 \mathrm{~m}$. Taking into account that this simulated layer is $400 \mathrm{~m}$ lower than the observed one, it is remarkable to note that the model is able to reproduce the $2000 \mathrm{~m}$ thickness of the layer as well as the aerosol mass concentration within a maximum error of $60 \%$.

Above the intermediate layer, the simulation also reproduces the upper layer (corresponding to the SAL) with a decrease of the mass concentration with altitude. An examination of the aerosol vertical profiles simulated over various points around Banizoumbou (at $0.5^{\circ}$ north, south, west and east of Banizoumbou) describing the limit of the area sampled by the aircraft is also shown on Fig. 11b. Small differences appear in the various simulated vertical structures, confirming that the whole region around Banizoumbou was characterized by the presence of three atmospheric layers $13 \mathrm{~h}$ after the MCS passage.

\subsection{Air mass origins}

The MesoNH tool allows us to determine the air mass origins using the lagrangian backtrajectories analysis of Gheusi and Stein (2002). This lagrangian approach is to transport position tracers that are able to precisely retrieve the trajectory of the simulated air mass (all implicit processes parameterized in a mesoscale model such as turbulence, convection, surface mixing, have been used to determine the evolution of tracers). Figure 12 shows the obtained backtrajectories ending at various altitudes $(500 \mathrm{~m}, 1500 \mathrm{~m}, 2000 \mathrm{~m}, 3000 \mathrm{~m}$ and $5000 \mathrm{~m}$ ) over Banizoumbou on 1 July 2006, 07:00 UTC, before the MCS passage. Two distinct groups are clearly visible. Group 1 is representative of air masses coming from Burkina-Faso that followed the monsoon flux and stayed in the BL. An ascent from the surface occurred near Banizoumbou. The monsoon flux mixed marine aerosols with continental pollution. Group 2 trajectories are characteristic of air masses originated from the Niger-Nigeria border $\left(6.4^{\circ} \mathrm{E}\right)$ and that followed the Harmattan flux. Trajectory altitudes at $3000 \mathrm{~m}$ and $5000 \mathrm{~m}$ were stable over $8 \mathrm{~h}$. Since the origin of the Harmattan flux is various desert regions with little anthropogenic influence, these air masses primarily contained dust particles with similar compositions. Thus, the origin difference for these air masses of group 2 is not likely to explain the change observed in aerosol properties.

Prior to convective activity, these two air mass groups remained decoupled and established two well marked layers over Banizoumbou. The upper layer was enriched by dust particles that are mostly hydrophobic and thus keep their original hygroscopic properties as long as they are not chemically modified. In the lower layer (monsoon flux) the particles were assumed to be hydrophilic due to the presence of more soluble particles. 

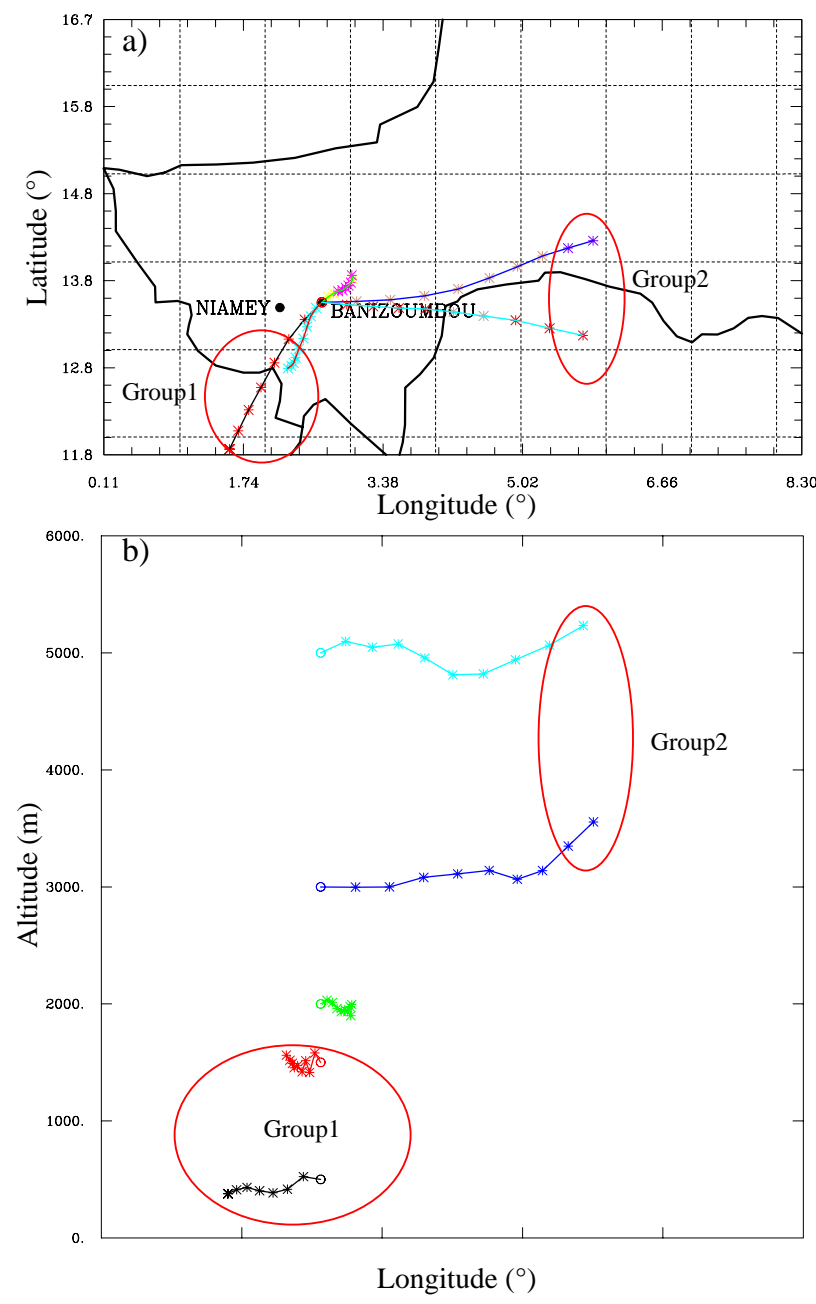

Fig. 12. Backtrajectories ending over Banizoumbou on 1 July 2006, 07:00 UTC. Timestep: $1 \mathrm{~h}$. (a) Horizontal projection. (b) West-east vertical projection.

Figure 13 shows the air mass backtrajectories ending over Banizoumbou at the same altitudes as Fig. 12 on 2 July 2006, 07:00 UTC, $12 \mathrm{~h}$ after the MCS passage. The start points of these backtrajectories were on 1 July 2006, 18:00 UTC and the MCS dissipated at midnight over Burkina-Faso. The monsoon flux (group 1) and the Harmattan flux (group 2) are, respectively, restored in the lower part of the $\mathrm{BL}$ and in the SAL. But a new group of air masses (group 3) appears between $1000 \mathrm{~m}$ and $2800 \mathrm{~m}$ from a region located north of Banizoumbou where they have crossed the MCS a few hours earlier (see Fig. 9). During the first $3 \mathrm{~h}$, one of the air masses descends by $4500 \mathrm{~m}$, indicating that the air mass follows the downdraft of the MCS. After the first $3 \mathrm{~h}$, the altitude of the group 3 air masses is stabilized in a layer where the airborne measurements indicated a decrease of $\mathrm{CN}$ concentration (see Fig. 5) and an increase of the CCN/CN ratio (see Fig. 6).

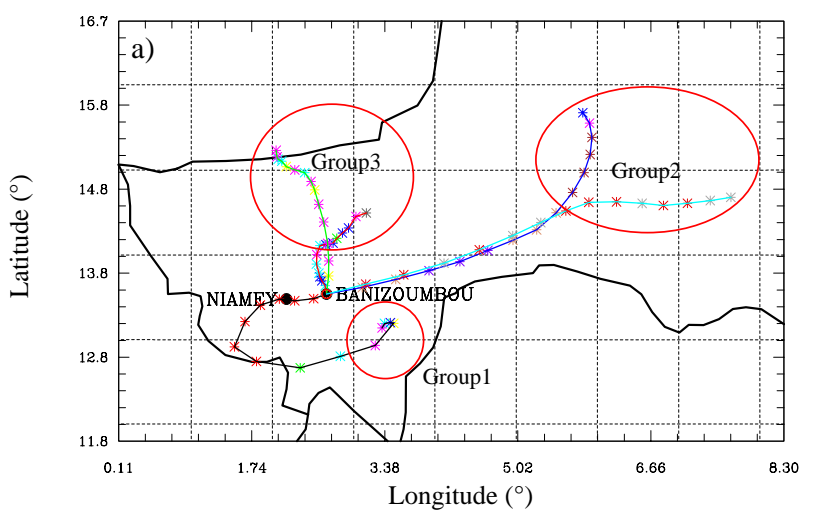

b)

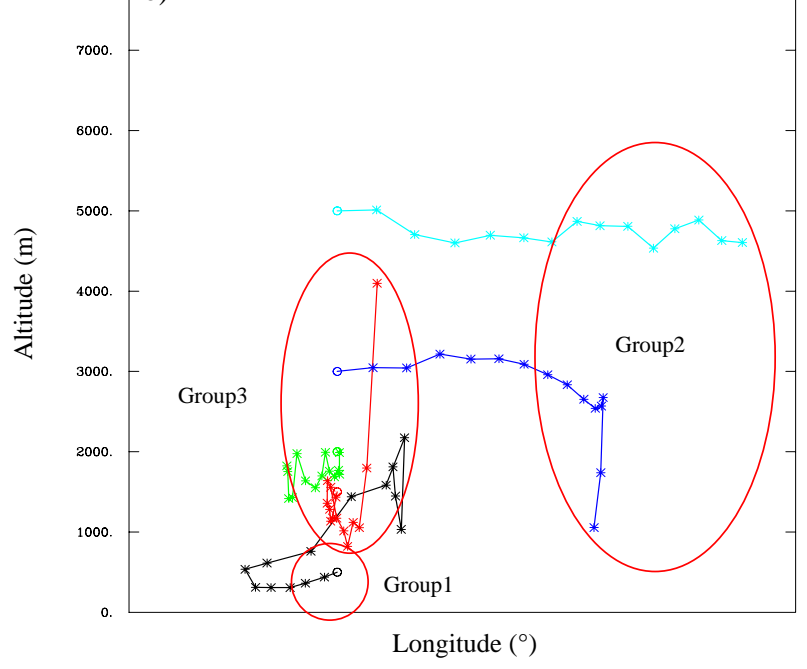

Fig. 13. Backtrajectories ending over Banizoumbou on 2 July 2006, 07:00 UTC. Timestep: 1 h. (a) Horizontal projection. (b) West-east vertical projection.

\subsection{MCS impact on aerosol dust distribution}

Figure 14 is a horizontal view of the computed surface mass concentration of dust on 1 July at 19:00 UTC. This pattern was obtained by summing the three populations of particles emitted and transported by the model, and integrated over the whole domain during the passage of the MCS. The area situated north of Niamey and Banizoumbou is characterized by high surface dust concentrations reaching $10000 \mu \mathrm{g} \mathrm{m}^{-3}$ and $5000 \mu \mathrm{g} \mathrm{m}^{-3}$, respectively. Chomette et al. (1999) used the infrared difference dust index and the reanalysis from the ECMWF to determine the threshold wind speed for soil erosion in Sahelian-Saharan regions. In Niger, near Niamey, they found that the wind speed must be higher than $6.5 \mathrm{~m} \mathrm{~s}^{-1}$ to generate emissions of dust particles. In Fig. 10c, the average surface wind speed over the whole domain is less than this threshold of $6.5 \mathrm{~m} \mathrm{~s}^{-1}$ except around the MCS where a downdraft generates a gust front with surface wind speed exceeding $15 \mathrm{~m} \mathrm{~s}^{-1}$. These surface winds are strong enough to move soil particles by saltation and generate high dust 


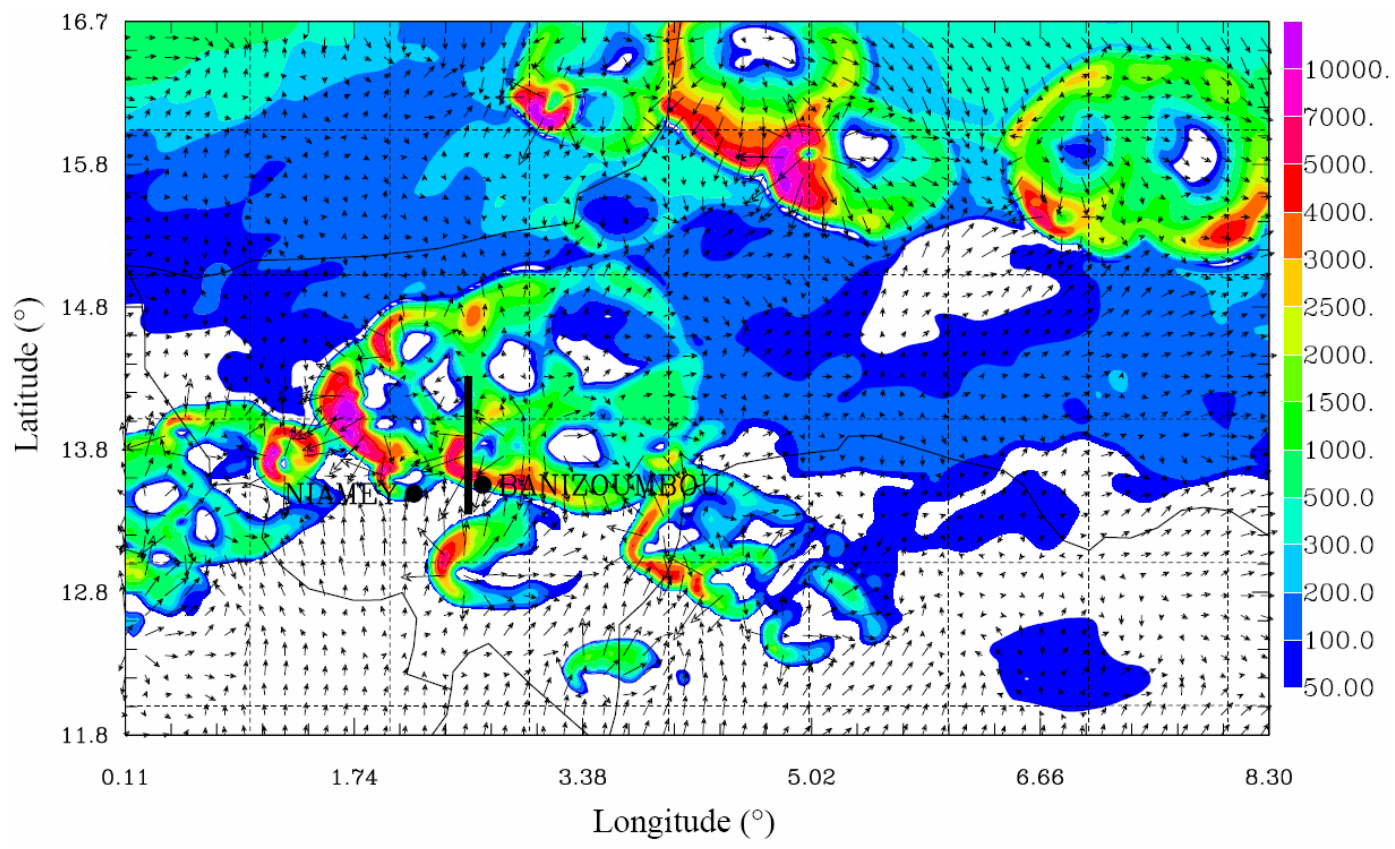

Fig. 14. Surface dust concentration $\left(\mu \mathrm{g} \mathrm{m}^{-3}\right)$ on 1 July 2006, 19:00 UTC. Vectors correspond to the surface wind speed. The maximum vector represents $16.2 \mathrm{~m} \mathrm{~s}^{-1}$.

concentration in surface as simulated by the model in front of the MCS. On the contrary, behind the MCS, precipitation scavenges the particles and inhibits dust generation by increasing the soil moisture. Hence, the surface dust concentration decreases to about $500 \mu \mathrm{g} \mathrm{m}^{-3}$ after the passage of the MCS.

The backtrajectories of Fig. 13 show that the air mass sampled by the aircraft between $1000 \mathrm{~m}$ and $2800 \mathrm{~m}$ on 2 July, $12 \mathrm{~h}$ after the MCS passage, crossed the MCS in a region situated north of Banizoumbou. In order to better understand the processes in which aerosols could be involved during the convection that took place north of Banizoumbou, a vertical cross section of the convective system is presented in Fig. 15. This cross section corresponds to the horizontal trace shown in Fig. 14. Figure 15a displays the vertical distribution of the cloud water mixing ratio (colored areas) and the mixing ratio of rain (isolines).

The simulation shows that the convective system was clearly mature with high concentrations of liquid water and ice content $\left(2 \mathrm{~g} \mathrm{~kg}^{-1}\right.$ at $5000 \mathrm{~m}$ and $4 \mathrm{~g} \mathrm{~kg}^{-1}$ at $16000 \mathrm{~m}$, tropopause) and an important overshoot up to $18000 \mathrm{~m}$. The vertical wind speed reached $20 \mathrm{~m} \mathrm{~s}^{-1}$ in the convective core. Below $5500 \mathrm{~m}$, at altitudes sampled $12 \mathrm{~h}$ later by the aircraft, significant precipitations occurred with a maximum of $3.4 \mathrm{~g} \mathrm{~kg}^{-1}$ at $3700 \mathrm{~m}$. The simulation also shows that evaporation is important, with a maximum of $60 \%$ of precipitation reaching the surface. Such precipitation generates intense surface winds of $16 \mathrm{~m} \mathrm{~s}^{-1}$ at the base of the convective core, the gust front.
In addition, Fig. $15 \mathrm{~b}$ gives the vertical dust mass concentration between the surface and $4500 \mathrm{~m}$ along the same cross section. In the northern part of this cross section, the computed vertical profile is characterized by dust concentrations of about $500 \mu \mathrm{g} \mathrm{m}^{-3}$ near the surface and $200 \mu \mathrm{g} \mathrm{m}^{-3}$ between 600 and $3000 \mathrm{~m}$. As shown before, the MesoNH simulates high dust concentrations reaching $5000 \mu \mathrm{g} \mathrm{m}^{-3}$ in front of the convective core, in a thin layer above the surface. An important fraction of this surface dust amount (500$1000 \mu \mathrm{g} \mathrm{m}^{-3}$ ) was lifted in the convective ascent. Where precipitation occurred, the dust mass concentration decreases to $150 \mu \mathrm{g} \mathrm{m}^{-3}$. This important horizontal gradient of aerosol concentration between scavenged and dry zones shows that an important mass of aerosols has been cloud-processed and evaporated as explained by Tulet et al. (2008). Indeed, it is reasonable to assume that the internal circulation of the MCS can mix long range transported dust from the SAL (northern part of the vertical cross section) with fresh dust generated by the MCS gust front and soluble material contained in the monsoon flux of the boundary layer (see surface backtrajectory of Sect. 5.4). This result is similar to the study of Levin et al. (1996) which determined three conditions that involve cloud processing: particles in an aqueous phase, presence of soluble element, and evaporation of droplets. Cloud processing is able to change the hygroscopicity of new particles by modifying their chemical composition (Meng and Seinfeld, 1994). Our results suggest that cloud processing could occur in this MCS event, as all conditions were present. First, various types of gas and particles provided by the monsoon 


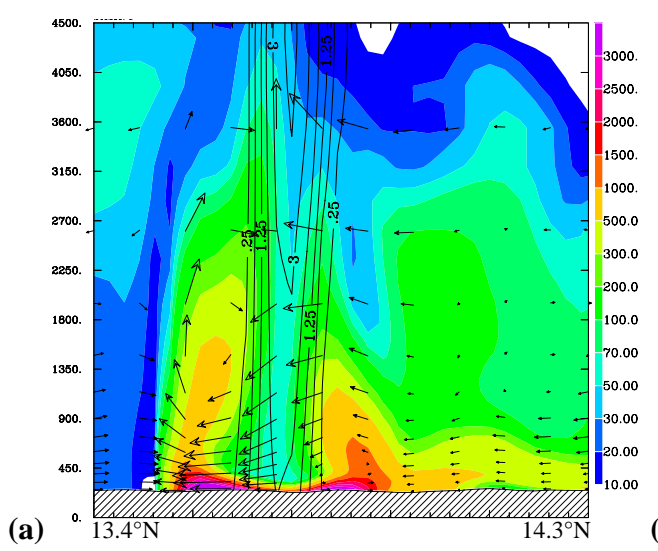

(b)

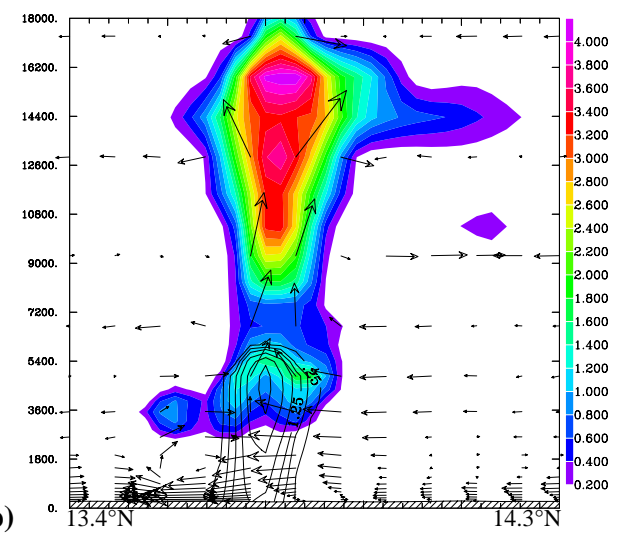

Fig. 15. Meridional cross section of the convective system (see location in Fig. 14) on 1 July 2006, 19:00 UTC. (a) Colored areas represent the mixing ratio for cloud and ice $\left(\mathrm{g} \mathrm{kg}^{-1}\right)$ and the isolines correspond to the mixing ratio for rain $\left(\mathrm{g} \mathrm{kg}^{-1}\right)$. (b) Colored areas represent the dust concentration $\left(\mu \mathrm{g} \mathrm{m}^{-3}\right)$ and the isolines correspond to the mixing ratio for rain $\left(\mathrm{g} \mathrm{kg}^{-1}\right)$. Vertical scales are not the same.

flux are mixed in an aqueous environment with mineral dust produced by the MCS itself. The particles are then collected by cloud drops that have originally been nucleated by soluble materials (like nitrates or sulfates) brought by the monsoon flux. Upon evaporation (Fig. 15a), modified aerosol particles having an increased ability to act as $\mathrm{CCN}$ are formed in the intermediate layer from mineral and soluble compounds and are left behind. Finally, the results of this simulation show that the African MCS's create conditions which are highly favorable for cloud processing. Furthermore, this process can explain the observations made in the intermediate layer after the MCS passage regarding the increase of the $\mathrm{CCN} / \mathrm{CN}$ ratio and the chemical modification of aerosols by coating of nitrate and other soluble material on coarse particles.

\section{Conclusions}

This paper describes the increase of aerosol hygroscopicity by aqueous mixing in a mesoscale convective system observed during the AMMA experiment by using a combination of airborne observations and simulation exercises. Airborne measurements of aerosol characteristics were carried out $12 \mathrm{~h}$ before and $12 \mathrm{~h}$ after a mesoscale convective system that passed over Banizoumbou, in Niger, on 2 July 2006 at 00:00 UTC. The flight plans were the same in order to avoid differences in environmental conditions. Observations were then interpreted using a mesoscale model simulation in order to explain the changes observed regarding aerosol properties.

Before the convection event, air mass backtrajectories show that two distinctive layers were identified over Banizoumbou. In the BL (at low level), air masses came from the monsoon flux. This layer is known to be associated with trace gases and hygroscopic aerosols. Above the boundary layer, backtrajectories analyses show that the air masses came from the northeastern desert regions and contained mineral dust particles. Before the convection, both layers were disconnected, explaining the difference in the $\mathrm{CCN} / \mathrm{CN}$ ratio observed. Indeed, dust particles in the SAL are mostly hydrophobic while aerosols present in the BL are more hygroscopic.

After the convection event, a third layer located between 1000 and $3000 \mathrm{~m}$ was identified with air masses coming from a region north of Banizoumbou. In the intermediate layer, the $\mathrm{CN}$ concentration decreased and a significant increase by a factor of 4 of the $\mathrm{CCN}$ fraction is also observed during the post-MCS period in comparison with the same ratio measured in the SAL before the convection. Moreover, the results of the elemental composition analyses of individual particles collected in this layer after the MCS passage showed a higher contribution of sulfate, nitrate and chloride to the total aerosol (in internal and/or external mixing with mineral dust), all of which being soluble and efficient CCN. On the other hand, in the BL, an increase of the volume concentration of coarse particles (mode centered on $2.59 \mu \mathrm{m}$ ) was also noted. In addition, the single particle analysis indicates a dominance of freshly emitted dust particles known to be rather hygrophobic. Thus, the CCN/CN ratio is kept steady between the pre-MCS and post-MCS periods.

The simulation shows that this intermediate layer originates from a region where the convective process generated an aqueous mixing of gas, aerosols within the monsoon flux, and mineral dust already present in the SAL or generated by the MCS gust front. In agreement with Levin et al. (1996) and Meng and Seinfeld (1994), the simulation results show that all conditions inside the MCS are highly favorable for cloud processing. Indeed, it is reasonable to assume that the MCS creates a soluble element coating around dust particles that enhance their hygroscopic capacities. 
This study shows that convective systems can mix aerosols from different origins and different layers in aqueous environment. Wet processes can modify externally mixed aerosols into an internal mixing of particles with a corresponding increase in hygroscopicity. In addition, our results confirm that dust lifting by the gust front of African MCSs is the principal mechanism to generate mineral aerosol in this region, during the monsoon season. The amount of lifted dust could even be estimated by the model. Finally, this study shows that a realistic mesoscale modeling is a major tool to improve our knowledge on the complex aerosol-cloud processes such as those observed during the AMMA campaign.

Acknowledgements. This work has been supported by the African monsoon multidisciplinary analysis (AMMA) project. Based on a French initiative, AMMA was built by an international scientific group and is currently funded by a large number of agencies, especially from France, UK, USA and Africa. The authors wish to thanks the SAFIRE (Service des Avions Francais Instruments pour la Recherche en Environnement) for preparing and delivering the research aircraft (ATR-42 and Falcon-20). The authors are grateful to A. Boone (CNRM) for the ISBA scheme and C. Lac, I. Mallet for the MesoNH assistance. Special Thanks to G. Roberts.

Edited by: P. Formenti

\section{References}

Alfaro, S. C. and Gomes, L.: Modeling mineral aerosol production by wind erosion: Emission intensities and aerosol size distributions in source areas, J. Geophys. Res., 106, D16, 18 075-18 084, 2001.

Barthe, C., Molinié, G., and Pinty, J. P.: Description and first results of an explicit electrical scheme in a $3 \mathrm{~d}$ cloud resolving model, Atmos. Res., 76, 1-4, 95-113, 2005.

Bechtold, P., Bazile, E., Guichard, F., Mascart, P., and Richard, E.: A mass-flux convection scheme for regional and global models, Q. J. Roy. Meteor. Soc., 127, 869-886, 2001.

Bougeault, P. and Lacarrére, P.: Parameterization of orographyinduced turbulence in a meso-beta model, Mon. Weather Rev., 117, 1872-1890, 1989.

Boone, A. and deRosnay, P.: Towards the improved understanding of land-surface processes and coupling with the atmosphere over west africa, iLEAPS Newletter, 3, 33-34, 2007.

Carlson, T. N. and Prospero, J. M.: The large scale movements of saharan air outbreaks over the northern equatorial atlantic, J. Appl. Meteorol., 11, 283-297, 1972.

Chaboureau, J.-P. and Pinty, J. P.: Validation of a cirrus parameterization with meteosat second generation observations, Geophys. Res. Lett., 33, L03815, doi:10.1029/2005GL024725, 2006.

Chomette, O., Legrand, M., and Marticorena, M.: Determination of the wind speed threshold for the emission of desert dust using satellite remote sensing in the thermal infrared, J. Geophys. Res., 104, 31 207-31 215, 1999.

Chin, M., Rood, R., Lin, S. J., Müller, J. F., and Thompson, A.: Atmospheric sulfur cycle simulated in the global model GOCART: Model description and global properties, J. Geophys. Res., 105, 24671-24 687, 2000.
Cohard, J. M. and Pinty, J. P.: A comprehensive two-moment warm microphysical bulk scheme, ii: $2 \mathrm{~d}$ experiments with a non hydrostatic model, Q. J. Roy. Meteorol. Soc., 126, 1843-1859, 2000.

Dentener, J. F., Carmichael, G. R., Zhang, Y., Lelieveld, J., and Crutzen, P. J.: Role of mineral aerosol as a reactive surface in the global troposphere, J. Geophys. Res., 101, 22 869-22 889, 1996.

ECMWF: IFS documentation. Technical report, ECMWF, ecmwf. int/research/ifsdocs/, 2004.

Fouquart, Y. and Bonnel, B.: Computation of solar heating of the Earth's atmosphere: A new parameterization, Beitr. Phys. Atmos., 53, 35-62, 1980.

Gard, E. E., Kleeman, M. J., Gross, D. S., Hughes, L. S., Allen, J. O., Morrical, B. D., Fergenson, D. P., Dienes, T., Galli, M. E., Johnson, R. J., Cass, G. R., and Prather, K. A.: Direct observation of heterogeneous chemistry in the atmosphere, Science, 279, 1184-1187, 1998.

Gheusi, F. and Stein, J.: Small-scale rainfall mechanisms for an idealized convective southerly flow over the Alps, Q. J. Roy. Meteor. Soc., 128A, 337-360, 2002.

Grini, A., Tulet, P., and Gomes, L.: Dusty weather forecast using the mesonh atmospheric model, J. Geophys. Res., 111, doi:10.1029/2005JD007007, 2006.

Isawa, Y. and Ono, A.: Nitron thin film method for detection of submicron nitrate particles and its application to atmospheric aerosols, J. Meteorol. Soc. Jpn., 57, 599-606, 1979.

Janicot, S., Ali, A., Asencio, N., Berry, G., Bock, O., Bourles, B., Caniaux, G., Chauvin, F., Deme, A., Kergoat, L., Lafore, J.-P., Lavaysse, C., Lebel, T., Marticorena, B., Mounier, F., Nedelec, P., Redelsperger, J.-L., Ravegnani, F., Reeves, C. E., Roca, R., de Rosnay, P., Schlager, H., Sultan, B., Thorncroft, C., Tomasini, M., Ulanovsky, A., and ACMAD forecasters team: Large-scale overview of the summer monsoon over West and Central Africa during the AMMA field experiment in 2006, Ann. Geophys., 26, 2569-2595, 2008, http://www.ann-geophys.net/26/2569/2008/.

Joseph, J. H., Wiscombe, W. J., and Weinman, J. A.: The DeltaEddington Approximation for Radiative Flux Transfer, J. Aer. Sci., 33, 2452-2459, 1976.

Karyampudi, V. M., Palm, S. P., Reagen, J. A., Fang, H., Grant, W. B., Hoff, R. M., Moulin, C., Pierce, H. F., Torres, O., Browell, E. V., and Melfi, S. H.: Validation of the Saharan dust plume conceptual model using lidar, Meteosat, and ECMWF data, B. Am. Meteorol. Soc., 80, 1045-1075, 1999.

Köhler, H.: Zur Thermodynamik der Kondensation an hygroskopischen Kernen und Bemerkungen über das Zusammenfliessen der Tropfen, Medd. Met. Hydr. Anst. Stockholm, 3, 8, 1926.

Lafore, J. P., Stein, J., Asencio, N., Bougeault, P., Ducrocq, V., Duron, J., Fischer, C., Héreil, P., Mascart, P., Masson, V., Pinty, J. P., Redelsperger, J. L., Richard, E., and Vilà-Guerau de Arellano, J.: The Meso-NH Atmospheric Simulation System. Part I: adiabatic formulation and control simulations, Scientific objectives and experimental design, Ann. Geophys., 16, 90-109, online available at: http://mesonh.aero.obs-mip.fr/mesonh/, 1998.

Levin, Z., Ganor, E., and Gladstein, V.: The effects of desert particles coated with sulfate on rain formation in the eastern mediterranean, J. Appl. Meteorol., 35, 1511-1523, 1996.

Mallet, M., Tulet, P., Serca, D., and Lohou, F.: A study of the impact of Saharan dust on the radiative forcing, surface energy budget and atmospheric dynamics over the west African region in March 
2006, J. Geophys. Res., submitted, 2008.

Mamane, Y. and Pueschel, R. F.: A method for the detection of individual nitrate particles, Atmos. Environ., 14, 629-639, 1980.

Mamane, Y. and Gottlieb, J.: Nitrate formation on sea-salt and mineral particle: a single particle approach, Atmos. Environ., 26A, 1763-1769, 1992.

Marticorena, B. and Bergametti, G.: Modeling of the atmospheric dust cycle: 1. design of a soil derived dust emission scheme, J. Geophys. Res., 100, 16415-16429, 1995.

Masson, V.: A physically-based scheme for the urban energy balance in atmospheric models, Bound.-Lay. Meteorol., 94, 357397, 2000.

Masson, V., Champeaux, J. L., Chauvin, F., Meriguet, C., and Lacaze, R.: A global database of land surface parameters at 1-km resolution in meteorological and climate models, J. Clim., 16, 9, 1261-1282, 2003.

Mathon, V., Laurent, H., and Lebel, T.: Mesoscale convective system rainfall in the sahel, J. Appl. Meteorl., 41, 1081-1092, 2002.

Matsuki A., Iwasaka, Y., Osada, K., Matsunaga, K., Kido, M., Inomata, Y., Trochkine, D., Nishita, C., Nezuka, T., Sakai, T., Zhang, D., and Kwon, S.-A.: Seasonal dependence of the long-range transport and vertical distribution of free tropospheric aerosols over east asia: on the basis of aircraft and lidar measurements and isentropic trajectory analysis, J. Geophys. Res., 108, 8663-8675, 2003.

Matsuki A., Schwarzenboeck, A., Venzac, H., Laj, P., Laurent, O., Crumeyrolle, S., Gomes, L., Bourrianne, T., Momboisse, G., Tobo, Y., and Iwasaka, Y.: Effect of surface reaction on the cloud nucleating properties of mineral dust: AMMA aircraft campaign in summer 2006, Atmos. Chem. Phys. Discuss., submitted, 2008.

Meng, Z. and Seinfeld, J. H.: On the source of submicrometer droplet mode of urban and regional aerosols, Aerosol Sci. Tech., 20, 3, 253-265, 1994.

Morcrette, J. J. and Fouquart, Y.: The overlapping of cloud layers in shortwave radiation parameterizations, J. Aer. Sci., 43, 321-328, 1986.

Murphy, D. M. and Thompson, D. S.: Chemical composition of single aerosol particles at Idaho Hill negative ion measurements, J. Geophys. Res., 102, 6353-6368, 1997.

Noilhan, J. and Mahouf, J.: The isba land surface parametrisation scheme, Global Planet. Change, 13, 145-159, 1996.

Parker, D. J., Thorncroft, C. D., Burton, R. R., and Diongue-Niang, A.: Analysis of the African easterly jet, using aircraft observations from the JET2000 experiment, Q. J. Roy. Meteorol. Soc., 131, 1461-1482, 2005.

Pinty, J. P. and Jabouille, P.: A mixed-phase cloud parameterization for use in mesoscale non hydrostatic model: simulations of a squall line and of orographic precipitations, Conference of Cloud Physics, Everett, WA, USA, 217-220, 1998.

Prospero, J. M. and Carlson, T. N.: Vertical and area distributions of Saharan dust over the western equatorial North Atlantic Ocean, J. Geophys. Res., 77, 5255-5265, 1972.

Pruppacher, H. R. and Klett, J. D.: Microphysics of clouds and precipitation, Kluwer, 954 pp., 1997.

Roberts, G. C., Andreae, M. O., Zhou, J., and Artaxo, P.: Cloud condensation nuclei in the Amazon Basin: Marine conditions over a continent?, Geophys. Res. Lett., 28(14), 2807-2810, 2001.
Seinfeld, J. H. and Pandis, S. N.: Atmospheric chemistry and physics: from air pollution to climate change, John Wiley \& Sons, Inc.,New York, USA, 1326 pp., 1998.

Snider, J. R. and Brenguier, J. L.: Cloud condensation nuclei and cloud droplet measurements obtained during ace-2, Tellus, 52B, 828-842, 2000.

Suhre, K., Mari, C., Bates, T. S., Johnson, J. E., Rosset, R., Wang, Q., Bandy, A. R., Blake, D. R., Businger, S., Eisels, F. K., Huebert, B. J., Kok, G. L., Mauldin III, R. L., Prévôt, A. S. H., Schillawski, R. D., Tanner, D. J., and Thornton, T. C.: Physicochemical modeling of the first aerosol characterization experiment (ace 1) lagrangian b, 1. a moving column approach, J. Geophys. Res., 103, 16433-16455, 1998.

Tost, H., Jöckel, P., Kerkweg, A., Sander, R., and Lelieveld, J.: Technical note: A new comprehensive scavenging submodel for global atmospheric chemistry modelling, Atmos. Chem. Phys., 6, 565-574, 2006, http://www.atmos-chem-phys.net/6/565/2006/.

Trigo, T. F., DaCamara, D. F., Viterbo, P., Roujean, J. L. Olesen, F., Camacho de Coca, F., Garcia-Haro, J., Geiger, B., GellensMeulenberghs, F., Meliá, J., and Siljamo, N.: The satellite application facility on land surface analysis, B. Am. Meteorol. Soc., submitted, 2008.

Tulet, P., Crassier, V., Solmon, F., Guedalia, D., and Rosset, R.: Description of the mesoscale nonhydrostatic chemistry model and application to a transboundary pollution episode between northern France and southern England, J. Geophys. Res., 108(D1), 4021, doi:10.1029/2000JD000301, 2003.

Tulet, P., Crassier, V., Cousin, F., Shure, K., and Rosset, R.: Orilam, a three moment lognormal aerosol scheme for mesoscale atmospheric model, on-line coupling into the mesonh-c model and validation on the escompte campaign, J. Geophys. Res., 110, D18201, doi:10.1029/2004JD005716, 2005.

Tulet, P., Crahan-Kaku, K., Crumeyrolle, S., and Gomes, L.: Mixing of dust aerosols into mesoscale convective system. An examination of the relative importance of downdraft generation and removal scavenging processes observed during the AMMA field campaign, International conference on cloud and precipitation, 2008.

Villani, P., Picard, D., Marchand, N., and Laj, P.: Design and Validation of a 6-Volatility Tandem Differential Mobility Analyzer (VTDMA), Aerosol Sci. Technol., 41(10), 898-906, 2007.

Wurzler S., T. G. Reisin, and Z. Levin : Modification of mineral dust particles by cloud processing and subsequent effects on drop size distributions, J. Geophys. Res., 105(D4), 4501-4512, 2000.

Yin, Y., Wurzler, S., Levin, Z., and Reisin, T. G.: Interactions of mineral dust particles and clouds: Effects on precipitation and cloud optical properties, J. Geophys. Res., 107, 4724, doi:10.1029/2001JD001544, 2002.

Zender, C. S., Bian, H., and Newman, D.: The mineral dust entrainment and deposition (DEAD) model: Description and global dust distribution, J. Geophys. Res., 108(D14), 4416, doi:10.1029/2002JD002775, dust.ess.uci.edu/dead/, 2003.

Zhuang, H., Chan, C. K., Fang, M., and Wexler, A. S.: Size distributions of particulate sulfate, nitrate, and ammonium at a coastal site in Hong Kong, Atmos. Environ., 33(6), 843-853, 1999. 